\title{
A City-Wide Approach to Carbon Finance
}

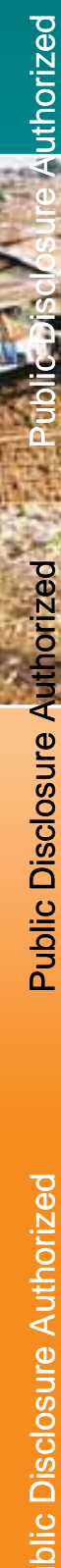

Carbon Partnership Facility Innovation Series

(円) THE WORLD BANK 



\section{A CITY-WIDE APPROACH TO CARBON FINANCE}

Carbon Partnership Facility Innovation Series

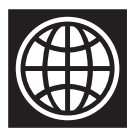

The World Bank

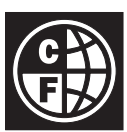

Carbon Finance Unit

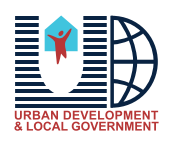

Urban Development Unit 
Copyright (C) World Bank, 2010

All rights reserved

Carbon Finance Unit

World Bank

1818 H Street, NW

Washington, DC 20433 USA

Tel: (202) 473-1000

Fax: (202) 477-6391

www.carbonfinance.org

This publication is a product of the staff of the World Bank Group. It does not necessarily reflect the views of the Executive Directors of the World Bank or the governments they represent. The World Bank does not guarantee the accuracy of the data included in this work.

This note is provided for information only. The World Bank has no responsibility for the persistence or accuracy of URLs and citations for external or third-party sources referred to in this publication and does not guarantee that any content is, or will remain, accurate or appropriate. 


\section{Foreword}

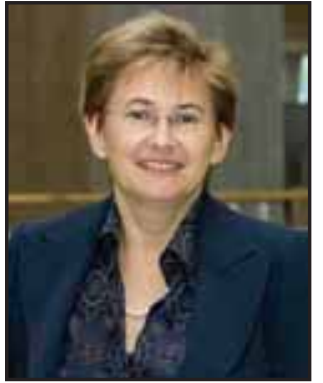

Joëlle Chassard Manager, Carbon Finance Unit Environment Department

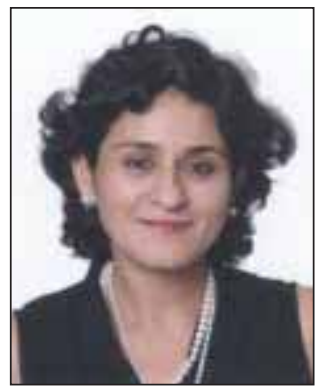

Abha Joshi-Ghani Manager, Urban Development and Local Government Unit Finance, Economics and Urban Development Department

Cities are essential to achieving sustainable development from economic, social, and environmental perspectives. By 2050, as many people will live in urban areas as the total world population in 2000. This enormous rate of urban growth highlights the challenges now faced by cities to ensure the provision of basic urban services while maintaining economic growth, protecting the environment, and strengthening social cohesion. However, these challenges also present unique opportunities to improve performance, increase efficiency, and reduce costs.

Carbon finance offers an opportunity to access financial resources to reduce the incremental costs of implementing projects that mitigate greenhouse gas (GHG) emissions in cities. Most GHG emission reduction projects provide significant ancillary local benefits, such as improved air quality, reduced commuting times, more sustainable natural resource use, reduced pollution, financial savings, and improved customer satisfaction for the users of services. While carbon finance activities have gained momentum, cities have been unable to reap the full benefit of participating in global carbon markets.

The Carbon Finance Unit and the Urban Development and Local Government Unit of the World Bank are pleased to jointly present this innovative approach to assist city authorities to develop city-wide carbon finance programs. This note presents an innovative aggregated approach that allows a city to develop a single strategic emission reduction program that can be implemented over several years, allowing the city to work within its budgetary constraints while addressing its development priorities.

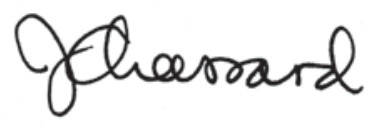

Joëlle Chassard

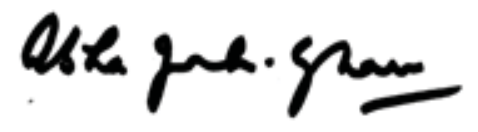

Abha Joshi-Ghani 


\section{Acknowledgements}

This note has been prepared by a core team led by Monali Ranade and Perinaz Bhada comprising Claudia Barrera, Harikumar Gadde, Julie Godin, Holly Krambeck, Charles Peterson, Nat Pinnoi, Alexandrina PlatanovaOquab, and Rama Reddy. The work was conducted under the guidance of Neeraj Prasad in the Carbon Finance Unit (ENVCF) and Daniel Hoornweg in the Urban Development and Local Government Unit (FEUUR).

The team is grateful for useful feedback and comments from Mila Freire, Ashok Sarkar, Alexandra le Courtois, Axel Baeumler, Rutu Dave, David George, Nanae Yabuki, Marcus Lee, Johanne Heister, and Hiroaki Suzuki,
Shahyar Niakan, and Isabel Hagbrink from the World Bank. The team benefited greatly from technical review and advice provided by Ranjan Bose and Jas Singh from ESMAP, Gaëell Mainguy of Veolia Environment Institute, Robert Kehew on behalf of UN-Habitat, Missy Stults from ICLEILocal Governments for Sustainability USA, Sh. Dharmendra for Government of Delhi, India, and Benoit Lefevre from IDDRI/ Sciences Po. The report would not have been possible without the encouragement and continuous inputs from numerous experts and colleagues within the World Bank Group, non-governmental organizations, private sector companies, and consulting firms. 


\section{Table of Contents}

vii Executive Summary

1 Introduction

5 Section I: Cities and Climate Change

9 Section II: Accessing Carbon Finance

17 Section III: Creating a City-wide Program to Reduce GHG Emissions

28 Section IV: Sectors and Interventions

30 Energy

37 Transport

42 Solid Waste

47 Water and Wastewater

50 Urban Forestry

54 Section V: Qualifications

55 Abbreviations and Acronyms

57 Glossary

60 References 


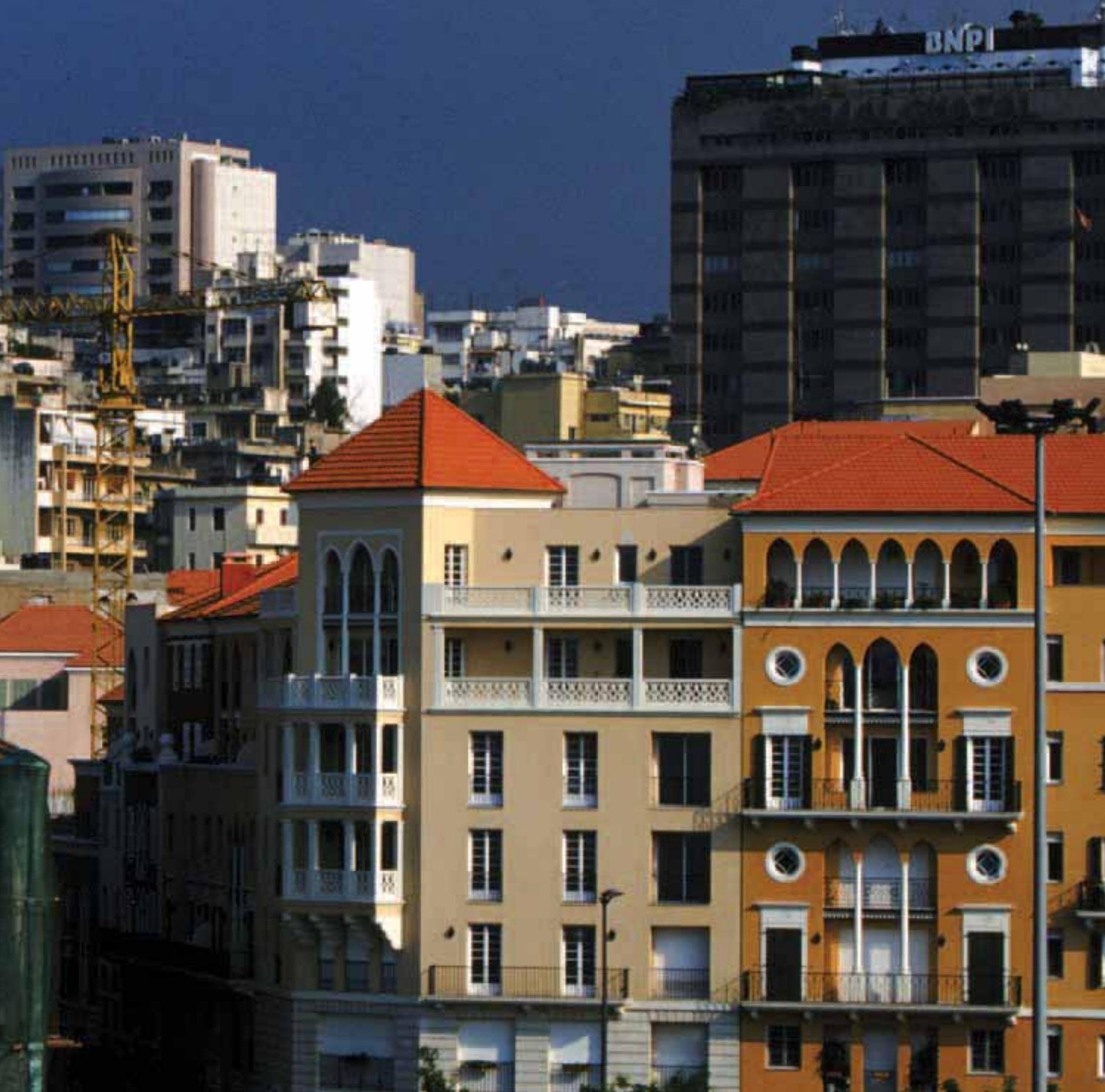




\section{Executive Summary}

Urbanization and climate change will define much of the 21st century. Urbanization leads to improvement in standards of living, and through the increased density and service delivery efficiency of cities, higher growth can be achieved with lower greenhouse gas emissions. Cities and urban agglomerations house more than $50 \%$ percent of the global population and contribute more than 70 percent of global greenhouse (GHG) emissions. As the share of urban population grows, sustainable urban development emerges as an essential component in addressing climate change. Mitigation often comes at a significant cost. Carbon finance has an important role to play in reducing these costs. Carbon finance is accessible through regulated mechanisms, such as the Clean Development Mechanism (CDM) and Joint Implementation (JI) under the Kyoto Protocol, and through voluntary markets, using the Voluntary Carbon Standard and climate exchanges. City authorities, however, have not been able to fully access market mechanisms for carbon credits. Less than $1 \%$ of projects registered with the CDM are credited to cities.

Cities are recognized leaders in mitigating GHG emissions; however, there are numerous reasons for the limited experience of cities in developing carbon finance projects. Three stand out: i. broader climate change mitigation priorities and actions have primarily been discussed at the level of national governments.

ii. individual city-level GHG emission reduction activities, such as efficiency improvement in street-lighting, are not large enough to warrant the transaction costs associated with carbon finance; and

iii. cities, especially those in developing countries, have limited financial resources and improving access to basic urban services receives greater priority.

There is, however, growing awareness that cities can fulfill their local needs while reducing their contribution of greenhouse gas emissions. Consequently, many cities around the world are voluntarily adopting mitigation targets as they realize the direct local benefits of these measures to cut costs, save energy, and to meet the broader goal of addressing climate change.

The city-wide approach to carbon finance is one of several key components that the World Bank and its partners are preparing in response to the urgent need to support cities in achieving sustainable development. Initiatives such as the Global City Indicators Program, Greenhouse Gas Index for cities, Rapid Assessment Framework, Eco ${ }^{2}$ : Ecological Cities as Economic Cities, and city-based vulnerability assessment would provide tools 
for cities to take comprehensive and effective action to improve quality of life.

This note introduces a city-wide approach to carbon finance. It proposes expansion of the CDM's Programme of Activities approach to enable aggregation of city-based GHG mitigation reductions broadly covered by five sectors: energy, transport, solid waste, water and wastewater, and urban forestry. This approach proposes a two-track effort to calculate GHG emission reductions: (i) measurement, using established CDM methodologies; and (ii) estimation, using simplified CDM methodologies or other sectorspecific calculation methods. The city-wide approach to carbon finance gives cities greater flexibility to create a GHG mitigation program covering one, a few, or all sectors, as part of a single comprehensive effort. Once a program is established, individual sector departments and agencies could propose new interventions over the lifetime of the program. This approach assumes that a comprehensive citywide 'transformation program' with emission reductions that can be monitored would provide cities greater access to carbon funds. Cities could use these funds to recover the additional cost of financing low-carbon, high-efficiency technology interventions, support effective implementation of mitigation policies and regulations, and develop the capacity to meet the requirements in terms of rigorous assessment and monitoring of emission reduction benefits.

This note draws on examples of local GHG mitigation interventions and expands the concept of CDM Programme of Activities to a multi-sector city-wide approach. The approach outlines steps to establish a citywide GHG emission reductions program, and discusses possible interventions to reduce GHG emissions. The steps include creation of a greenhouse gas inventory; establishment of a coordination office; identification of departments and agencies in each of the sectors; establishment of program boundaries and eligibility in accordance with cityspecific circumstances; and quantification of, implementation, monitoring of sector-specific interventions and emission reductions.

The approach presented in this document refers extensively to CDM methodologies and is limited in terms of the sector-specific nonCDM methodologies available to estimate emission reductions. This approach is highly flexible and can be expanded to include innovative interventions and new methods to calculate emission reductions across the five sectors. This approach can also be applied to any one sector, such as transport, for specific interventions, such as fuel switching in vehicle fleets or as an integrated transit-oriented approach. It is important to note that the citywide approach is a generic program design. The approach can be used to access funds from various sources: (i) carbon markets governed by CDM and JI; (ii) voluntary markets, including the promotion of carbon-neutrality for conferences, sporting and other public events; (iii) unique city-wide emissions trading programs; and (iv) national and international climate mitigation funds. 
ENERGY: Electrical and thermal demand; energy sources

TRANSPORT: Public transportation; private modes

SOLID WASTE: Treatment and disposal of waste; recycling

WATER AND WASTEWAT
disposal of wastewater

13 URBAN FORESTRY: Parks; gardens; street trees

use over the next 20 years will be from nonOECD countries (IEA 2008).

Cities, especially the denser city cores are, by their nature, more efficient in providing basic services than corresponding suburban or rural areas. Cities in the developing world, where most of the growth will take place, can have a significant positive impact on GHG emissions by investing in low-carbon technologies and energy efficiency measures. The primary sources of GHG emissions in a city are energy generation and use, transport, solid waste, and water and wastewater, while urban forestry provides an important service as a GHG sink. Technologically superior opportunities exist in all sectors; however, since many of these are considerably more expensive than conventional technologies, cities often find it difficult to justify their selection.

This document presents a city-wide approach to carbon finance and is intended for city administrators and officials, carbon finance project developers, and those in related fields. This carbon finance approach is more 
than the sum of multiple individual sector interventions. It attempts to factor in the numerous interdependencies between the various sector efforts and the corresponding direct local benefits. Cities, especially those in developing countries, often have competing priorities and few resources to meet their goals. The technological and policy interventions in the five sectors proposed in Section IV are meant to serve as an indicative list of actions that cities could consider implementing as they provide numerous direct local benefits including lower costs, job creation, reduced energy use, reduced pollution, improved environment, and consequently an overall enhancement of quality of life.

Carbon finance can provide a unique incentive for cities to assess, reduce, and monitor GHG mitigation initiatives. Although carbon finance is not a means to fund projects fully, it is typically a component in a larger investment strategy to provide sufficient resources and technical expertise to implement these activities. Carbon finance enables cities to estimate and incorporate potential energy savings and environmental and climate mitigation benefits into their development and operational plans.

The city-wide approach to carbon finance presented in this document would enable cities to combine various initiatives into a single program to generate emission reduction credits (ERs). Cities would have the flexibility to combine relevant technology options across different sectors given their financial and development abilities, thus lowering the transaction and administration costs that would otherwise have been required to set up individual carbon finance projects.

This approach is designed keeping in mind that GHG emissions in developing country cities are likely to grow in the coming decades as urbanization and per capita incomes increase. It does not require overall $\mathrm{GHG}$ emissions in a developing country city to decrease, in absolute terms, but that they decrease relative to the business-as-usual case through the implementation of various technological and policy interventions that also have direct local benefits.

The extent of emission reductions achieved by a city-wide program is limited only by the ambition of the city authorities and their ability to access finance to implement the activities. With the help of the GHG inventory and quantification of emission reductions from the implemented intervention, cities can plot their emissions trajectory and control their cumulative impact on the local and global environment as shown in Figure 1.

This new approach builds on the CDM programmatic approach and refers to relevant CDM methodologies for quantification of the emission reduction benefits. The approach proposed in this document aims to expand the CDM Programme of Activities (PoA) to a multi-sector approach, thus giving cities the flexibility to create their own city-wide GHG mitigation strategies and access carbon finance. The city-wide approach, as presented in this 
FIGURE 1 Illustrative GHG emissions trajectory for a city

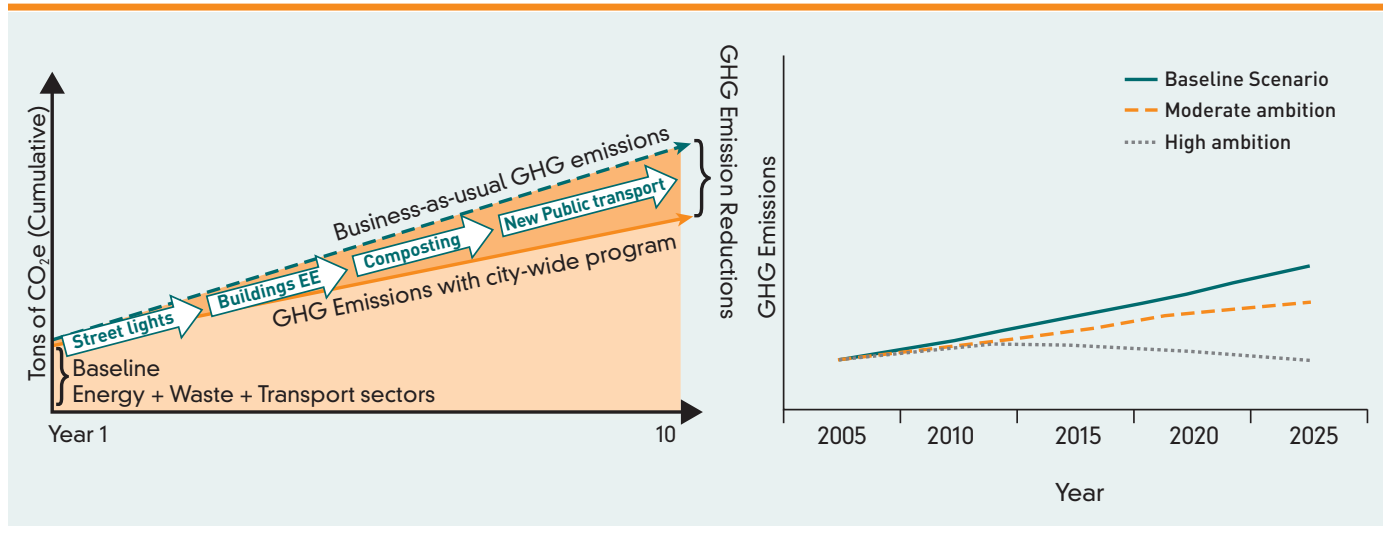

document, has not yet been considered by the CDM Executive Board and cannot be directly applied for developing a CDM PoA and generating Certified Emissions Reductions (CERs).

This document also explores alternative opportunities to quantify emission reductions and proposes a two-pronged approach: 'measurement,' based on CDM methodologies, and 'estimation' based on per unit impact of each activity. This approach is explained in Section III. Though this document refers extensively to CDM methodologies and PoA, the citywide approach in itself can be implemented by a city outside the realm of CDM as well. For instance, such a program could be developed as part of a voluntary scheme for trading ERs. GHG emission reductions under the CDM are traded as CERs; however, emission reductions are also traded as Verified Emission Reductions (VERs) and used by industries, companies as well as event organizers, and increasingly even tourists to offset their carbon emissions or to achieve carbon neutrality in their operations. GHG emission reductions achieved by a welldesigned city-wide program can access the different markets based on the interventions, volumes, and emission reduction quantification approaches.

This document provides an initial review of the development of a city-wide carbon finance program. Section I describes the need for climate change mitigation in cities; Section II discusses carbon finance opportunities and barriers; Section III provides the context and framework for a city-wide GHG mitigation program; Section IV discusses the technology and policy options for the five key areas of intervention-energy, transport, solid waste, water and wastewater, and urban forestrythat together make up the framework of a citywide program; and Section V discusses the limitations of the current approach and ideas for further development of this approach. 


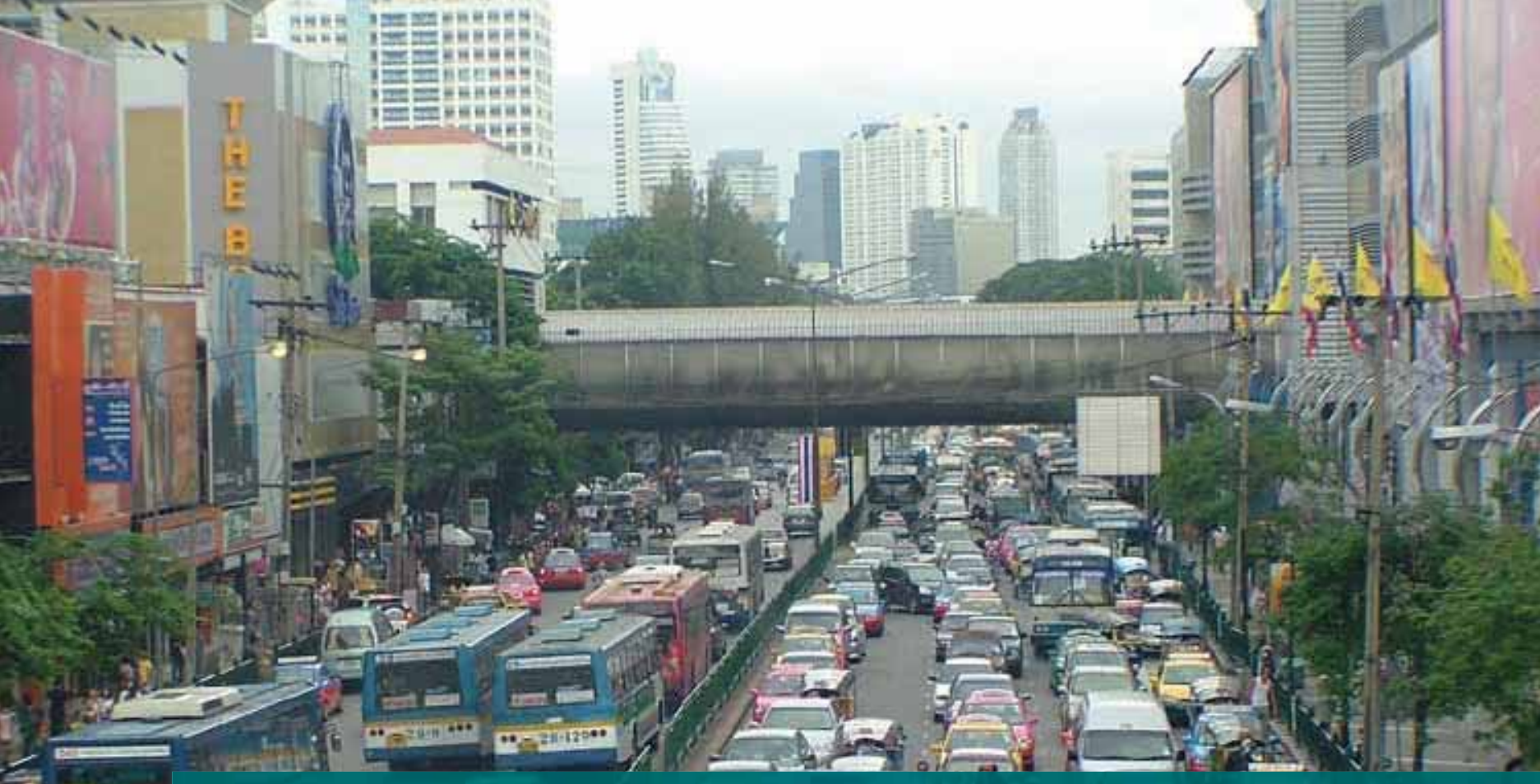

\section{SECTION I}

\section{Cities and Climate Change}

Why are cities important?

Today, one out of every two people lives in an urban area. Twenty years from now, 60 percent of the total population will live in cities; by 2050 this share will have grown to 75 percent (UN 2007). Most of this growth will take place in the developing world. This rapid urban growth presents numerous opportunities for sustainable economic growth and human development.

Urbanization could also pose significant economic, social, and environmental risks if not managed correctly. More than one billion people live in slums today. In Sub-Saharan
FIGURE 2 Share of urban and rural population in 2010 and 2050 (UN 2007)
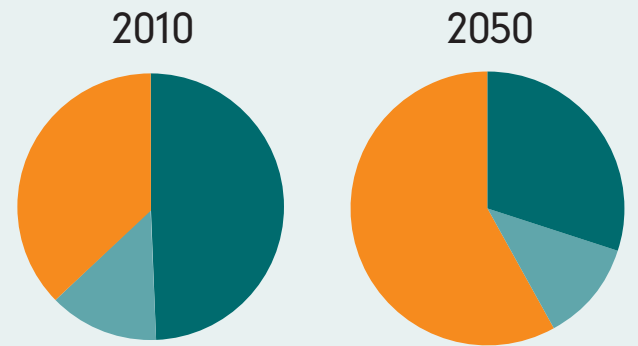

Rural

Urban (industrialized countries)

Urban (developing countries) 
Africa and South Asia, where the urban population is expected to double in the next two decades, between 40 and 70 percent of the population currently lives in slums (UN 2007). As the standard of living of the poorest urban dwellers improves and as cities begin to provide basic levels of water supply, sanitation, electricity, and housing, the amount of energy used and the associated greenhouse gas emissions will correspondingly increase.

Between 2000 and 2030, while urban population in developing countries is expected to double, the corresponding built-up area is expected to triple to $600,000 \mathrm{sq}$. $\mathrm{km}$. (Angel 2005), which means that significant amounts of energy and infrastructure will be required to support the growth of urban areas. Thus, investments in long-lived capital stock, such as transportation networks and energy supply, should move toward low-carbon and highenergy efficient technologies as quickly as possible.

Cities, especially those in developing countries, face a number of competing priorities including service delivery, public health, emergency response, and disaster risk management, to name a few. Climate change adds an overarching complexity to these tasks.

\section{Why does climate change matter?}

The impacts of climate change are already being felt around the world. According to the latest Intergovernmental Panel on Climate Change (IPCC) report, the average global
Warming of the climate system is unequivocal, as is now evident from observations of increases in global average air and ocean temperatures, widespread melting of snow and ice, and rising global average sea level.

_IPCC WG I Summary for Policy Makers, 2007

temperature has increased by $0.76^{\circ} \mathrm{C}$ and sea level has risen by $17 \mathrm{~cm}$ since the 19 th century (IPCC 2007).

In addition to changes in mean climate conditions, climate change will also bring about alterations in climate variability and extreme events. Impacts can vary on temporal and geographical scales, ranging from drought to flooding, more heat waves, and an increase in the frequency and intensity of extreme events, such as cyclones. Indirect impacts, such as decreases in food production, fresh water availability, and rapid ocean acidification, will also affect global economic growth and standard of living. Developing countries will disproportionately bear the consequences of climate change because they are more exposed, less resilient, and have low adaptive capacity to climate hazards (World Bank 2010). Coastal and low-lying cities are particularly vulnerable to the increased incidences and unpredictability of natural disasters.

Climate change is caused by the emission of greenhouse gases. There are six greenhouse gases recognized under the Kyoto Protocol- 
carbon dioxide $\left(\mathrm{CO}_{2}\right)$, methane $\left(\mathrm{CH}_{4}\right)$, nitrous oxide $\left(\mathrm{N}_{2} \mathrm{O}\right)$, hydrofluorocarbons (HFC), perfluorocarbons (PFC), and sulphur hexafluoride $\left(\mathrm{SF}_{6}\right)$ — that are released through various anthropogenic activities such as power generation, wastewater treatment, landfills, industrial processes, and fuel for transportation. Power generation for electricity, heat, and industrial activities makes up the bulk of global emissions, followed by land use change (e.g., deforestation and burning), agriculture (including livestock and use of fertilizers), and transportation (fossil fuels for automobiles).

FIGURE 3 Global $\mathrm{CO}_{2}$ e emissions by sector, 2004 (Rogner et al. 2007)

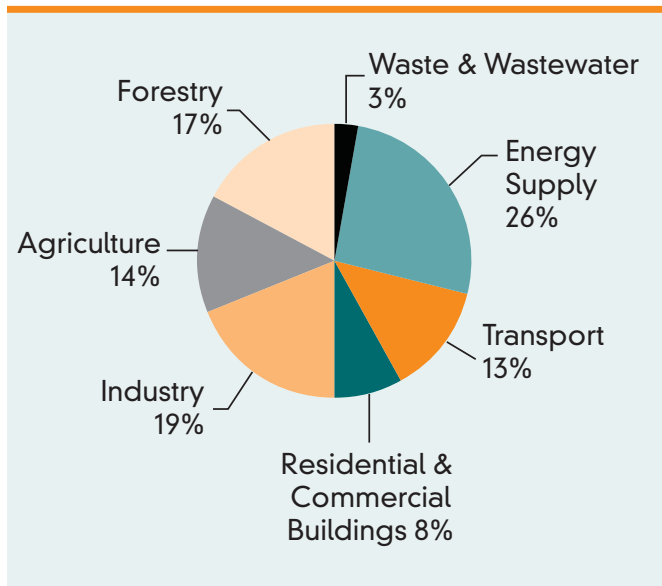

\section{How do urbanization and climate change impact each other?}

There is a strong link between urbanization, economic growth, and greenhouse gas emissions. Cities are engines of economic growth that contribute to a country's development and hence improve the standard of living of the country's citizens. Urban areas contribute to a significant portion of a country's GDP through industrialization, manufacturing activities, and provision of services - the same activities that result in the creation of greenhouse gases. Urban areas also concentrate people and as their affluence increases GHG emissions are further driven up by people's consumption patterns and lifestyle choices. On the other hand, a compactly designed city may well result in a lower volume of GHG emissions than would otherwise be obtained.

Historically, developed countries have had greater GHG emissions than developing countries. As urbanization skyrockets in the developing world in the coming decades, it is likely that GHG emissions will increase further. The amount of GHG emissions associated with urban areas is widely debated. According to

FIGURE 4 Per capita GHG emissions $\left(\mathrm{tCO}_{2} \mathrm{e}\right)$ year) in selected cities around the world (Kennedy et al. 2009)

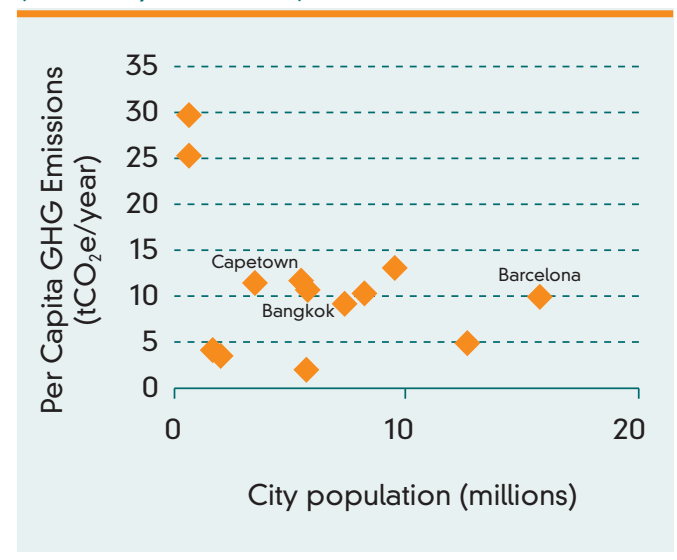


IEA estimates, urban areas currently account for over 71 percent of global greenhouse gases and this share is expected to rise to 76 percent by 2030 . It is estimated that 89 percent of the increase in $\mathrm{CO}_{2}$ from energy use will be from developing countries (IEA 2008).

There is a critical need for both adaptation as well as mitigation measures at the city level. Adaptation enables cities to better withstand the impacts of climate change, while mitigation enables cities to reduce their contribution to climate change. Adaptation and mitigation measures must be structured in such a way that they complement each other. This is particularly important since citiesas the most local level of governmentintegrate issues better and have minimal differentiation across departments and policies. City governments are usually structured around service provision objectives rather than policy directives more common in national governments. The response to climate change

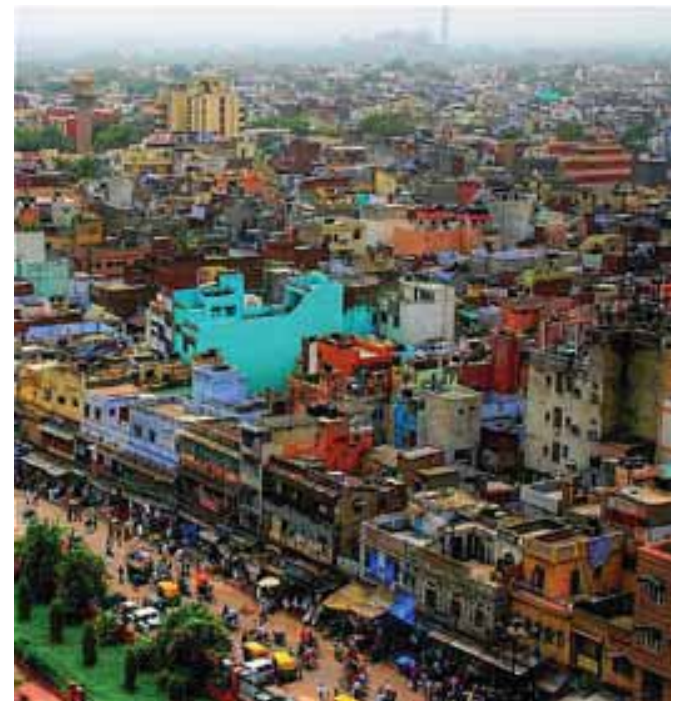

illustrates the unique perspective of cities which does not categorize response to climate change as mitigation, adaptation, and finance, as do international negotiations. Cities view climate change as another-albeit a majoraspect that needs to be incorporated into the city's overall service provision programming. 


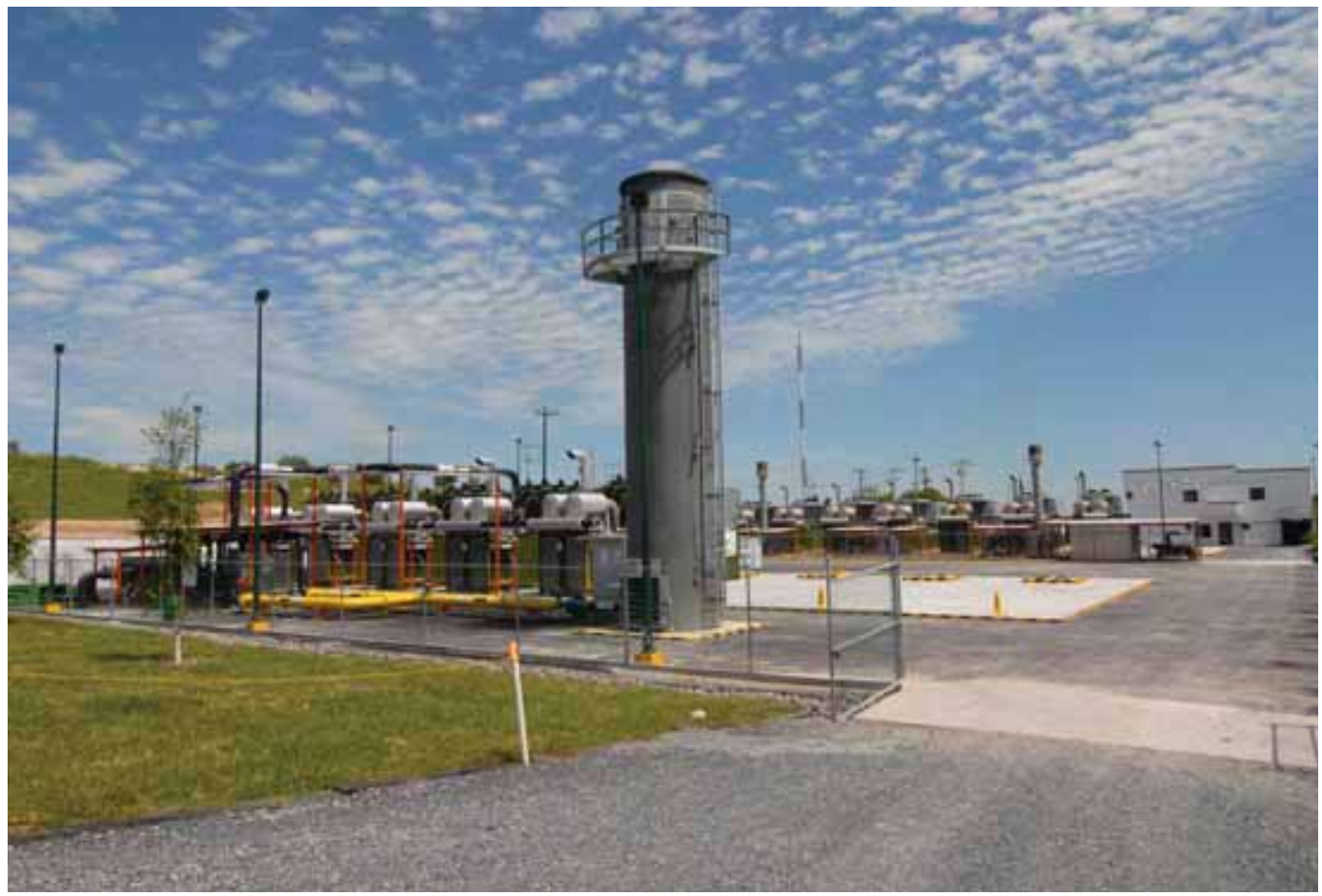

Trading Scheme - ETS); or (iii) invest in emission reduction projects in transition economies through the JI program or in developing countries through the CDM.

The main objectives of the CDM are twofold: (i) to help developed countries meet their emission reduction commitments through projects in developing countries; and (ii) to enable developing countries to achieve sustainable development from lowcarbon or high-energy efficient technologies. Carbon finance projects, particularly under CDM, have their own sets of advantages and disadvantages. The mechanism enables projects in developing countries to access additional sources of financing if they can demonstrate that the project is generating emission reductions additional to those in the baseline or 'business-as-usual' scenario. As the CDM is a performance-based incentive, project developers need access to upfront resources for implementation. By its nature, the CDM is easy to combine with other sources of financing, as it adds to the revenue stream of the project. However, the uncertainty of registering CDM projects has restricted the ability of project developers to leverage future CDM revenue to access upfront finance.

The mechanism also requires clear attribution and a high degree of certainty in defining 
correlation between an intervention and its corresponding impact in terms of GHG emission reductions. The CDM regulatory system reviews and approves methodologies for quantification of emission reductions, provides tools for assessing additionality and other technical requirements, and establishes rules and procedures for registering projects and issuing carbon credits. While an international system is useful in creating globally accepted procedures and protocols, adherence to these same requirements can also act as major barriers for successful development of GHG emission reduction projects.

A CDM baseline and monitoring methodology is the standard for calculation of emission reductions. All approved methodologies are available on the CDM website as a public good and can be freely used by all project developers, but creation or revision of these methodologies can be a highly cumbersome and time-consuming activity. CDM has largely been a 'learningby-doing' process with on-going changes to the rules and guidelines which have resulted in significant complexity in developing projects. The project-based approach itself has several disadvantages, especially in sectors where emission sources and stakeholders are dispersed, the volume of emission reductions is small, and several simultaneous policy and technology interventions are required to achieve emission reductions. Defining a clear correlation between any one intervention and its share of the emission reductions is extremely difficult. The next section describes the programmatic approach to CDM, which attempts to address some of the issues inherent to a project-based approach and which will be used as the basis for implementing the citywide approach presented in this document.

\section{CDM in cities}

As of December 2009, more than 1,900 $\mathrm{CDM}$ projects have been registered with the Secretariat of the United Nations Framework Convention on Climate Change (UNFCCC), the entity responsible for registering, approving, and monitoring projects and another 2,600 are in the pipeline for registration. These projects cover 15 sectors including agriculture, waste, transport, and energy and the use of one or more of the 148 approved CDM methodologies. CDM methodologies include the measurement of reductions in greenhouse gas emissions compared to baselines, which represent 'business-as-usual' trends, for specific sources of emissions, and monitoring the resultant emission reductions. There are more than 40 approved methodologies that are relevant to urban areas. The number of registered CDM projects in urban areas is approximately 150 , of which more than $90 \%$ are in the solid waste sector.

There are several reasons for the small number of CDM projects in cities. First, climate change mitigation and reductions in greenhouse gas emissions have historically been considered to be more of a priority for and the responsibility 
of national rather than local governments. Second, cities are generally more concerned with immediate development priorities, such as expanding access to urban services and slum upgrading. Generally, cities are more focused on local and immediate benefits in terms of environmental quality, economic growth, and social development. Unless the direct local benefits of $\mathrm{GHG}$ emission reduction projects can be meaningfully quantified, which is often burdensome to do, city authorities may continue to find it difficult to justify expenditures on these projects. Third, the administrative and transaction costs of setting up CDM projects in cities have been very high compared to the return from carbon finance. While it is possible to integrate a city's development objectives with the benefits resulting from emission reductions by choosing low-carbon technologies, improving efficiency, and enabling good management of natural resources, such efforts require regulatory support, technical expertise, and appropriate incentives.

For example, landfill gas (LFG) capture combined with power generation at a solid waste facility is a project eligible under the CDM and has multiple direct local benefits. Most countries do not mandate LFG capture as a solid waste disposal method and even in countries where it is required, widespread non-compliance is common. However, LFG technology provides two-fold emission reduction benefits: (i) avoidance of methane emissions from the decomposition of solid waste; and (ii) generation of electricity, which coupled with the high global warming potential (GWP) of methane, 23 times that of carbon dioxide, results in significant ER benefits and CDM incentives. LFG capture also reduces the amount of local air pollution associated with the generation of fossil fuelbased electricity and allows the solid waste facility to save money on electricity costs which can be used for upgrades or other purposes.

Water supply is another good example. With most cities struggling to expand potable water services, availability of funds for systematic improvements in the water system is desired but often considered impractical. Moreover, most public procurement systems are unable to fully incorporate life cycle costs, thus hindering the purchase of high-efficiency but higherpriced equipment. Wastewater management is of growing importance for cities. Wastewater treatment is often energy intensive and can generate significant nitrous oxide, a powerful greenhouse gas.

Energy efficiency projects face another unique challenge due to the expected replacement of inefficient equipment within the technical lifetime of the equipment. Most city-level agencies in developing countries have severely limited financial resources and find the scrapping of equipment that functions, even those with lower-efficiency, difficult to justify.

Transport-related infrastructure, in particular public transport, provides very high social, environmental, and economic benefits. However, these projects have smaller volumes 
of emission reductions in any given year, relative to some other sectors, masking the fact that such large-scale technological or policy interventions are essentially locked-in and will last for several decades thus cumulatively providing a wide-range of benefits over time. The transport network — or 'bones' of the cityskeleton-is also a key driver in related impacts such as housing type, land use, and lifestyle.

However, there is a compelling need to implement municipal-level GHG mitigation projects as they present significant direct local and GHG mitigation benefits. This is demonstrated in Figure 5, which provides the marginal abatement cost curve for Mexico. This curve summarizes the net costs and benefits of undertaking a range of potential initiatives in the country. The left-hand side of the curve (below "0"), which indicates interventions with net mitigation benefits, includes activities that a city can implement and manage successfully. These activities include bus system optimization, urban densification, improved street-lighting, increase in utility efficiency, solar water heating, efficient commercial and residential airconditioning, and so on. Each activity results

FIGURE 5 Marginal abatement cost curve for Mexico (recreated from Johnson et al. 2009)

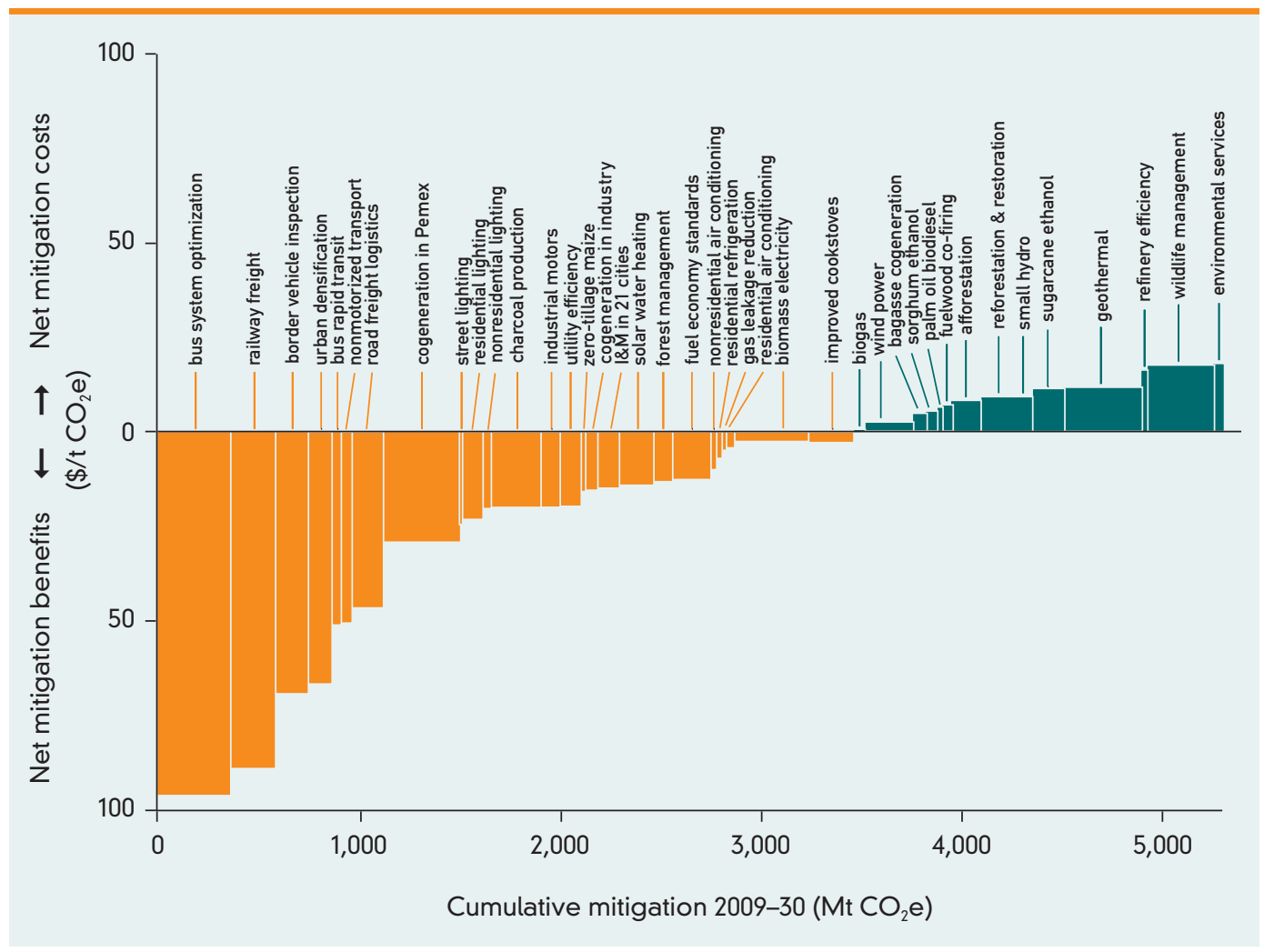




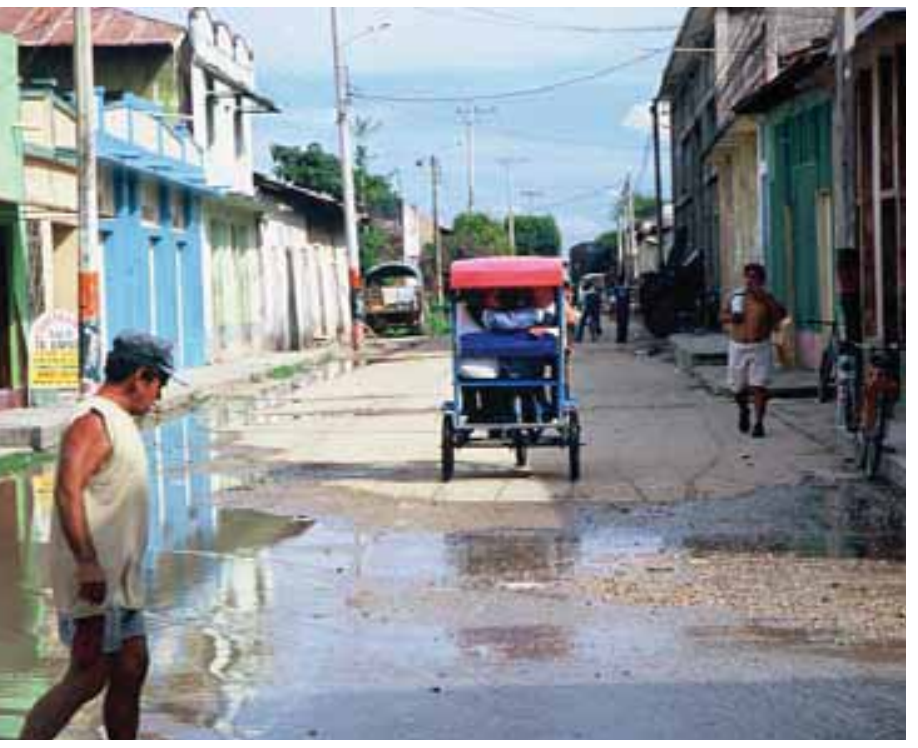

in GHG emission reductions but individually none of the measures produces enough emission reductions to provide significant carbon revenue-based incentives.

\section{Aggregating interventions}

Aggregating various technological options at the city level would achieve a scale of emission reductions suitable to access carbon markets. Aggregation is widely practiced in investment-focused programs. Lines of credit, establishment of cooperatives, and sectorspecific financing programs are all examples of channeling funds to achieve a common objective. The key difference is the scale, technological scope, and the nature of the aggregator. A crucial characteristic of such an aggregated programmatic approach is to enable alliances between public and private agencies, as well as financial and policy instruments.

\section{Eco ${ }^{2}$ Cities: Ecological Cities as Economic Cities}

This an initiative launched by the World Bank to provide practical and scalable, analytical and operational support for cities in developing countries to achieve ecological and economic sustainability. The framework is rooted in four interrelated principles: (1) 'A City Based Approach,' which enables local governments to lead a development process that takes into account their specific circumstances, including their local ecology; (2) 'An Expanded Platform for Collaborative Design and Decision Making' that accomplishes sustained synergy by coordinating and aligning the actions of key stakeholders; (3) 'A One System Approach' that enables cities to realize the benefits of integration by planning, designing, and managing the whole urban system; and (4) 'An Investment Framework that Values Sustainability and Resiliency' by incorporating and accounting for life cycle analysis, the value of all capital assets, and risk assessments in decision making.

Source: www.worldbank.org/eco2 


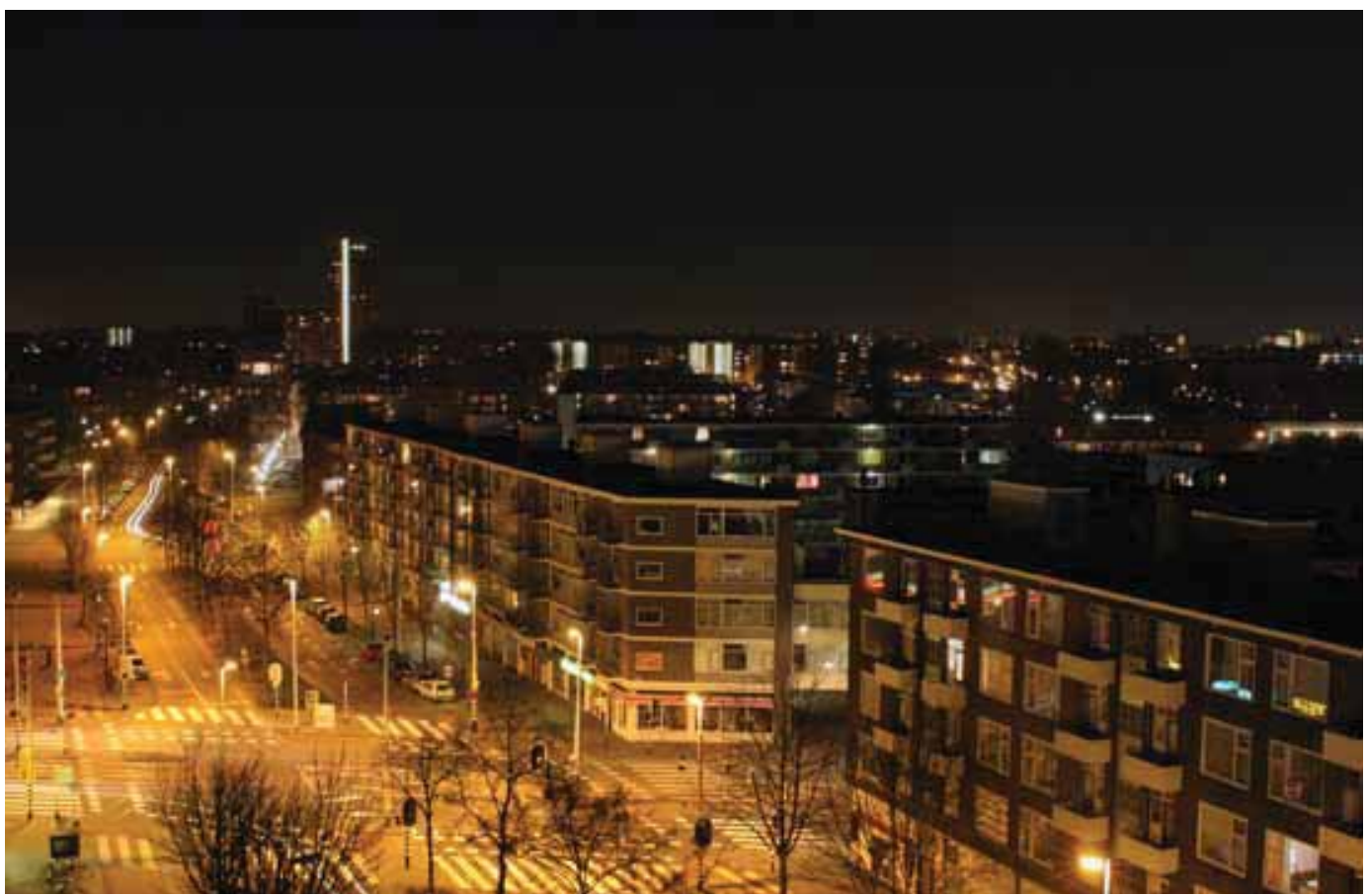

Broadly, aggregation can be categorized as vertical and horizontal.

Vertical aggregation represents a multiplicity of similar actions in a given sector or sub-sector (e.g., large-scale replacement of light bulbs, high-efficiency appliances, vehicle improvement programs). The main coordinating actors of these aggregations could be central, regional, or local governments, or utilities.

\section{Horizontal aggregation represents a} multiplicity of actions coordinated by an agency across a range of sectors or sub-sectors (e.g., initiatives targeting energy efficiency in buildings, low-carbon transport, or urban forestry programs in a city). A program run by a city government could encompass a range of activities in its area of jurisdiction, with direct interventions in its own activities and regulatory and incentive-based initiatives that facilitate the participation of private sector and the community at large. While the concept of aggregation is used in this document in its narrower connotation as 'aggregation for GHG emission reductions', approaches such as the $\mathrm{Eco}^{2}$ Cities use it as a 'one-system approach' for urban areas.

In most cases, there are certain natural aggregators, mandated either by laws, such as government agencies, or by their stakeholders, such as industry associations. These natural aggregators exist in almost all countries, 


\section{Mexico City's Climate Change Action Plan}

Climate change is a horizontal issue that cuts across and brings together the main components of Mexico City's environmental and development policies, including those related to energy, water, mobility, soil conservation, economic development, waste generation and management, vulnerability, and environmental education. Transportation is considered in the context of the mobility, expansion, and improvement of public transportation. The expansion of infrastructure for more sustainable transportation forms and the change in transportation use habits towards non-motorized mobility constitute a group of actions and public policies that, at the same time, propose to guarantee the mobility of goods and people and reduce GHG emissions in the atmosphere.

In the framework of the Mexico City Climate Action Program, policies and actions regarding efficient water use and supply are linked to those dealing with risks. On the question of energy, GHG emission mitigation actions in the capital city include energy saving and efficiency measures, the promotion of the use of solar energy, and, increasingly, the promotion of renewable energy sources. With regards to solid waste, the measures taken to avoid waste generation and to recycle and utilize its energy content all have a broad, clear environmental and economic orientation. Soil conservation actions, such as land restoration, care of the soil, and surface area expansion through zone recovery, contribute to mitigating GHGs by increasing carbon capture and reducing the city's vulnerability to extreme climate events. Any strategy geared towards dealing with climate change should continually address the population's information and training needs and include educational activities so that the society can identify everyday practices contributing to GHG emissions and decide what we can do to reduce our vulnerability and to increase our ability to adapt.

A total of 26 greenhouse gas mitigation actions, across the sectors mentioned above, have been proposed in the Mexico City Climate Action Program; if implemented, they will reduce the $\mathrm{CO}_{2}$ equivalent emissions by 4.4 million tons a year, which represents $12 \%$ of the annual GHG emissions in Mexico City.

Source: Excerpts from Mexico City Climate Action Program 2008-2012 Summary and C40 Cities Climate Leadership Group

though with differing degrees of technical capacity, institutional support, and financial capability. The fastest way to scale-up activities effectively is to support such aggregators by developing program frameworks, building their capacity, and providing access to financial incentives, such as carbon credits. The following section provides guidance on the development of a city-wide program for GHG mitigation. 


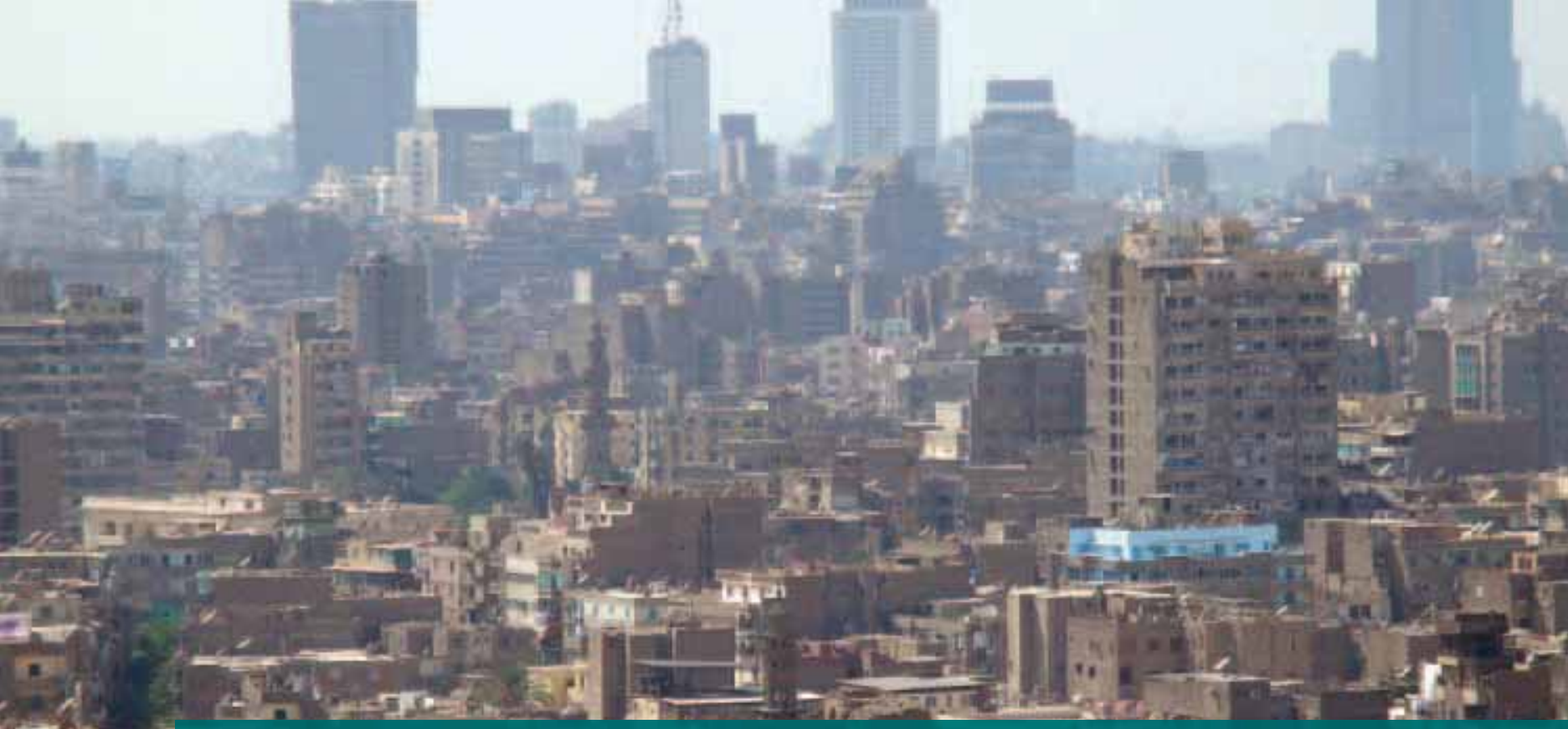

\section{SECTION III}

\section{Creating a City-wide Program to Reduce GHG Emissions}

A program can be defined as a set of activities implemented over a period of time to achieve a specific objective. The overall objective of the city program is reduction in $\mathrm{GHG}$ emissions while providing multiple local economic, environmental, and social benefits. If a city is considered a single administrative unit, emissions within its geographical boundaries can be broadly classified into emissions from activities controlled by the city authorities and emissions from activities they can influence. Most local governments control basic urban services such as housing, roads, public transit, street lighting, solid waste management, and the distribution, collection, and treatment of water and wastewater. They are also able to influence
GHG emissions in the city by enforcing building codes, economic development activities, planning or zoning laws, and user charges.

This section provides a generic roadmap for the development of a GHG emission reduction program at the city level, based on guidelines provided under the CDM. While the establishment of a GHG baseline or inventory and a coordination office are considered essential, the remaining steps could be customized to fit city-specific circumstances.

There are two distinct approaches to designing a GHG emission reductions program at the city level: (i) a top-down approach based on a 


\section{Project $2^{\circ}$}

Project $2^{\circ}$ is a web-based emissions tracking software, developed by the Clinton Climate Initiative $(\mathrm{CCl})$ and Microsoft Corporation, along with ICLEl-Local Governments for Sustainability, Ascentium Corporation, and the Center for Neighborhood Technology, that enables cities to calculate municipal and community GHG emissions. The software also allows cities to create action plans and monitor their emission reductions measures. In the first phase, $\mathrm{CCl}$ is working with the $\mathrm{C} 40$ Large Cities Climate Leadership Group.

For more information: www.project2degrees.org

GHG inventory; and (ii) a bottom-up approach based on identified sectors and interventions.

The GHG inventory approach has been available for almost two decades. ICLEI-Local Governments for Sustainability has led this effort with its Urban $\mathrm{CO}_{2}$ Reduction Project and the Harmonized Emissions Analysis Tool (HEAT) model. Generally, the inventory approach assesses the total emissions in a city, in terms of direct and indirect emissions, for all sectors and produces an action plan for the reduction of total emissions.

The bottom-up approach is based on creating a program that identifies sectors, stakeholders, and interventions and enables attribution of emission reductions to specific interventions. The city-wide approach, described in this document, combines the two approaches to ensure an upfront understanding of the city's GHG performance, in terms of its inventory; a statement of political will, in terms of the program objective; and participation of departments and agencies, in terms of identifying specific GHG emission reduction interventions.

\section{CDM Programme of Activities}

The framework of the CDM was expanded in 2005 from a project-by-project GHG emission reduction approach to include a programmatic approach to GHG mitigation. This approach considers policies and programs as key drivers of project activities that will reduce emissions across regions and over a period of time and with greater flexibility in implementation. CDM Programmes of Activities (PoAs) are coordinated activities, executed by a single entity that implements policies, measures, or goals leading to GHG mitigation. This document uses the terms "program" and "programme of activities" interchangeably as this city-wide aggregation approach can also be used to access carbon finance beyond CDM.

Carbon finance activities are based on a set of basic concepts: 


\section{CDM Programme of Activities}

A PoA is a voluntary coordinated action by a private or public entity which coordinates and implements any policy/measure or stated goal (i.e. incentive schemes and voluntary programmes), which leads to anthropogenic GHG emission reductions or net anthropogenic GHG removals by sinks that are additional to any that would occur in the absence of the PoA, via an unlimited number of project activities.

Boundary: This defines the characteristics of the program in terms of: spatial - physical location; $G H G$ - greenhouse gases mitigated by the activity; and even temporal - lifetime of the activity;

- Baseline scenario: The GHG emissions scenario in the absence of a project activity;

- Project scenario: The GHG emissions scenario after implementation of program interventions. The difference between the baseline and the project scenario is the reductions in GHG emissions;

- Leakage: Ensures that good practice within the program does not result in any negative impacts outside the project boundary, i.e., an increase in GHG emissions elsewhere;

Approach for quantification of ERs: All CDM projects use a methodology applicable to specific project activities. A methodology defines the baseline and project scenarios and provides the technical approaches and algorithms for calculation of emission reductions from a project activity; and
Monitoring emission reductions: This is also based on the methodology and is needed to monitor key technical and physical parameters of the project to assess the quantity of emission reductions. This forms the basis of verification of the emission reductions by a third-party leading to generation of carbon credits.

\section{Creating a city-wide program}

A city-wide approach to carbon finance would follow the basic principles of a CDM PoA. The following steps describe how a city could establish a city-wide GHG emission reduction program.

\section{Establish a coordination office for the program}

Cities are complex, multi-layered entities comprising political, administrative, and technical agencies. A number of urban services are contracted to private agencies to manage or operate. Typically, this results in highly disaggregated operations. For a city to harness its GHG mitigation potential it is important to bring together various stakeholders in the city. Carbon finance, in particular, and performance-based program management, in general, require structured reporting and incentivizing in order to be successful. To this end, the coordination office in a city should be established at the highest possible political or administrative level, which could be the Office of the Mayor or the City Manager. 
- Establish a coordination office for the program

- Establish geographical and sector boundaries for the program

- Develop an inventory of GHG emissions in the boundary 3

- Identify responsible departments and agencies

- Create appropriate incentives for relevant stakeholders 5

- Identify interventions and establish program eligibility 6

- Establish system for documentation and quality control 7

- Implement and monitor interventions

8

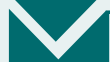

- Quantify emission reductions: measure or estimate

- Validate or verify ER benefit

10

As the name suggests, the coordination office would spearhead the program and lead different agencies and projects towards the common goal of reducing emissions in the city. This office can act through an advisory board, comprised of the heads of the relevant departments, and could be supported by a technical unit that manages the data collected from the project-related activities. Apart from the technical and administrative requirements, the coordination office is also the face of the program and will be responsible for communication with the public. This can be a useful approach to create awareness and gather support for the initiative.

The program design does not expect that city agencies would fund or implement all the activities themselves. The agencies are expected to lead the different stakeholders by providing them access to carbon finance and/or other 


\section{Carbon Finance Capacity Building program in emerging mega-cities of the South}

The Carbon Finance Capacity Building (CFCB) Program of the World Bank Institute, in conjunction with $\mathrm{C} 40$, assists cities in developing countries to access carbon finance for GHG mitigation activities. The CFCB Program facilitates this knowledge building by raising awareness of city officials and other stakeholders, highlighting projects for potential implementation, supporting institutional networking, and advising on project implementation. The CFCB provides continuous on-site, expert support and financing for each city for three years.

For more information: www.lowcarboncities.info

financing options to undertake these activities. The performance-based payment approach of carbon finance could facilitate adequate/ appropriate monitoring and reporting by the project staff.

\section{Establish the program boundary}

The city-wide approach inherently allows a city the flexibility to establish its own roadmap with the overarching goal to reduce GHG emissions over a fixed number of years. A city would have the flexibility of setting the boundary, whether it is based on municipal limits, i.e., having direct control over an expanded region, or as a metropolitan area, i.e., in cooperation with its neighboring municipalities. Within the geographical area, the city can decide whether to limit activities that are directly under its control, i.e., emissions due to provision of urban services, or to also include residential and commercial sector activities that the city can influence but has no control over. While it is advisable to include all sectors in the program, at this stage, a city could decide to limit the program to specific sectors.
The boundary is also set in terms of which GHGs would be covered by the program. This would limit the type of project activities that can be included in the program. The program approach defined in this document and the methodologies discussed in later sections limit the GHG boundary to $\mathrm{CO}_{2}$ and methane; however, depending on the technological interventions proposed this could be expanded to include other greenhouse gases.

\section{Develop a GHG inventory}

Greenhouse gas inventory tools for cities have been developed by various agencies. These inventory tools allow a city or local authority to assess its total GHG impact. A GHG inventory is a useful approach to quantify the gross impact of a city's contribution to overall GHG emissions, but is not oriented towards the establishment of a direct correlation between an intervention (policy or technology) implemented by the city, and its impact in terms of quantity of GHG emission reductions. This principle of "traceability" is the cornerstone of CDM. 


\section{Greenhouse Gas Index for Cities}

The World Bank is assisting in the development of an 'open-sourced,' globally relevant and harmonized protocol for quantifying the GHG emissions attributable to cities and local regions. The purpose is to establish a common standard to inventory city GHG emissions by including principles developed by the IPCC and following the WRI/WBCSD protocol to include out-of-boundary emissions that are driven by activities in cities. The GHG emissions embodied in the food, water, fuels and building materials consumed in cities are also reported as additional information items. This agreement also includes a standard reporting format for GHG emissions from cities and would be consistent with national inventories. This standard does not imply that local governments are responsible for these emissions, but that the inventory reflects the carbon dependence of the urban economy and highlights the extensive experience that local governments already have in monitoring GHG emissions. The effort is intended to: (i) build on the considerable experience of cities already publishing their GHG inventories and organizations such as ICLEl and C40/CCl; (ii) foster cost-effective and rapid creation of inventories and regular updating for all cities, say over 1 million people; and (iii) facilitate comparison of all existing and upcoming city-based GHG inventories. The inventory is seen as a minimal 'starting point' and many cities have more detailed break-downs.

For more information: www.worldbank.org/urban

An inventory is more appropriate in situations where gross reductions in $\mathrm{GHG}$ emissions are expected as compared to the baseline scenario. Most cities in the developing world are in a mode of expansion-increasing population, expanding geographical areas, and growing per capita incomes - all of which will result in an increase in GHG emissions in the coming decades. The aim of this city-wide approach is to help cities grow sustainably and to provide more urban services or support a higher number of residents at the same or reduced level of GHG emissions. To this end, undertaking GHG inventory periodically will provide a city with a broader view of its GHG impact on the climate.

\section{Identify relevant departments and agencies}

This requires developing an organization flow and mapping the agencies that would be responsible for developing and implementing projects for different sectors. This step involves identification of relevant government, nongovernment, and private contractors responsible for specific urban services, e.g., 
water pumping, bus transport, as well as administrative and technical staff responsible for specific technological interventions. A welldesigned program should be developed using a combination of a top-down and a bottom-up approach, where the city sets its ambitions at a macro level with inputs from individual departments. Each department can then be required to identify specific $\mathrm{GHG}$ emission reduction measures to be included in the citywide program. Once specific projects have been identified, the same departments would be required to establish monitoring and reporting systems and to support verification of actual emission reductions. The relevant departments and agencies would report to the coordination office on all aspects of the program.

\section{Create incentives}

Development, implementation, and monitoring of GHG emission reduction interventions requires significant effort beyond the normal operations of a project, and it is important to provide incentives to the department or agency undertaking such an activity. Incentives can be in the form of financial benefits or as awards and recognition. A portion of the revenue from carbon finance programs could be shared with the specific department that is responsible for implementation, operation, and monitoring of the GHG mitigation intervention. Ideally, incentives should be commensurate with the level of emission reductions achieved by the particular project and department.

\section{India's City Development Plans}

The Government of India is implementing the Jawaharlal Nehru National Urban Renewal Mission (JNNURM) that utilizes the process of preparing a City Development Plan (CDP) to develop a good understanding of activities within a city. The goal of the mission is to create economically productive, efficient, equitable and responsive cities. A CDP presents the current stage of the city's development-where are we now? It sets out the directions of change-where do we want to go? It identifies the thrust areas-what do we need to address on a priority basis? It also suggests alternative routes, strategies, and interventions for bringing about the change-what interventions do we make in order to attain the vision? It also provides a framework and vision within which projects need to be identified and implemented. The resulting City Investment Plan and financial alternatives provide a key starting point for creating a formal urban renewal program. The assessment of GHG emissions resulting from the alternatives could convert this program in a city-wide carbon finance program.

Source: http://jnnurm.nic.in/nurmudweb/brochure.aspx 
The coordinating authority should retain a portion of the revenue to cover the costs of implementing the program. Awards and recognition are important incentives that enhance performance of individual staff members and teams within departments and for departments and agencies in a city.

\section{Identify interventions and establish program eligibility}

Once the boundary conditions are defined, the city can establish the program's eligibility criteria. These criteria are important in defining the additionality of the emission reductions achieved by each activity and the entire program. Assessment of additionality ensures that the financial incentives, in terms of ER revenue, are not spent on an activity that would have happened anyway and that the activity does indeed yield emission reduction benefits over-and-above those in the baseline scenario.

Interventions can be identified and prioritized for implementation. This decision can be based on internal priorities, financing availability, or the payback period. However, as the city-wide approach focuses on emission reductions, there is also the option to assess projects on the basis of their overall GHG emission reductions, local benefits, and energy and economic cost savings. There are various tools available for cities to estimate the local and GHG benefits from specific projects, including CDM methodologies and estimation indicators described in the following section, and tools developed by the private sector such as Accenture's Integrated Smart City Model.

The lifetime of a program can range from the short-term (less than 5 years) to the longterm (more than 10 years). The city also has the flexibility to identify interventions that could be implemented at varied timelines or schedules, based on the city's internal priorities, availability of funds, or payback period. An illustrative list of sectors and interventions and their suggested payback periods is presented in Table 1. Such a list can be used to establish the program framework.

\section{Energy Efficient Cities Initiative:}

The Energy Efficient Cities Initiative (EECl), launched by the Energy Sector Management Assistance Program (ESMAP), is a program that identifies innovative ways to improve energy efficiency in the delivery of city services and reduces the costs and environmental impacts of energy use. The Rapid Assessment Framework (RAF), a central component of the EECl, is a practical tool to enable cities to review existing systems, identify areas of energy use for further focus, provide a menu of options and recommendations to save energy, and lower costs to make the city energy efficient and to guide potential future investment by $\mathrm{EECl}$.

For more information: www.esmap.org 
TABLE 1 Indicative economics of sustainable energy options (Adapted from Suzuki et al. 2009)

\begin{tabular}{|c|c|c|c|}
\hline $\begin{array}{l}\text { Technology/ } \\
\text { Intervention }\end{array}$ & $\begin{array}{l}\text { Short-Term Payback } \\
\text { (under } 5 \text { years) }\end{array}$ & $\begin{array}{l}\text { Medium Term Payback } \\
\text { (5-10 years) }\end{array}$ & $\begin{array}{l}\text { Long Term Payback } \\
(10+\text { years })\end{array}$ \\
\hline \multirow[t]{2}{*}{$\begin{array}{l}\text { Energy } \\
\text { (Demand-side) }\end{array}$} & $\begin{array}{l}\text { Equipment retrofits; } \\
\text { Labeling building } \\
\text { performance; ESCO } \\
\text { contracting }\end{array}$ & $\begin{array}{l}\text { Building envelope } \\
\text { measures; Green roofs }\end{array}$ & $\begin{array}{l}\text { Building codes } \\
\text { Certification of building } \\
\text { materials }\end{array}$ \\
\hline & $\begin{array}{l}\text { Lighting retrofits using high } \\
\text { efficiency lamps; } \\
\text { Redesign of lighting systems }\end{array}$ & Retrofits using LEDs & $\begin{array}{l}\text { Street and traffic lighting } \\
\text { standards }\end{array}$ \\
\hline $\begin{array}{l}\text { Energy } \\
\text { (Supply-side) }\end{array}$ & $\begin{array}{l}\text { Supply-side loss reduction; } \\
\text { Power factor correction; } \\
\text { Retrofits of boiler and piping } \\
\text { systems }\end{array}$ & $\begin{array}{l}\text { Combined heat and power; } \\
\text { Load management }\end{array}$ & \\
\hline $\begin{array}{l}\text { Renewable } \\
\text { Energy }\end{array}$ & Renewable energy standards & $\begin{array}{l}\text { Promotion of distributed } \\
\text { generation with feed-in } \\
\text { tariffs }\end{array}$ & \\
\hline Transport & $\begin{array}{l}\text { Optimization of traffic } \\
\text { signals; Fuel efficiency } \\
\text { vehicle standards; } \\
\text { Congestion taxes/tolls }\end{array}$ & $\begin{array}{l}\text { Alternative fuels for public } \\
\text { buses, taxis; } \\
\text { Bus rapid transit systems }\end{array}$ & $\begin{array}{l}\text { Modal shifts; } \\
\text { Vehicle inspection and } \\
\text { maintenance; Changes in } \\
\text { land use patterns }\end{array}$ \\
\hline Solid Waste & & $\begin{array}{l}\text { Methane recovery for power } \\
\text { generation from landfills; } \\
\text { Recycling programs }\end{array}$ & \\
\hline $\begin{array}{l}\text { Water and } \\
\text { Wastewater }\end{array}$ & $\begin{array}{l}\text { Pumping retrofits; } \\
\text { Right-sizing of pumps; } \\
\text { Leak reduction; } \\
\text { Load management }\end{array}$ & $\begin{array}{l}\text { System optimization; } \\
\text { Methane recovery for power } \\
\text { generation; } \\
\text { Reduced water use }\end{array}$ & \\
\hline
\end{tabular}

\section{Establish system for documentation and quality control}

The share of carbon revenue retained by the program entity, e.g., a city's coordination office, can be used to provide technical advisory services for the projects as well as to undertake documentation and quality control of the data submitted by projects. The program coordination office is responsible for the verification of energy savings/emission reductions and is, therefore, required to ensure proper reporting of projects and, if required, substantiated with site visits to understand the progress and status of the project. This step is critical in the generation of carbon credits.

\section{Implement and monitor the interventions}

This includes overseeing the implementation and operation of projects through a system 
of fiscal oversight, scheduled progress reports, and site visits. Monitoring should also involve the development of a rewards system that acknowledges performance, quality, and efficiency of the project activity. While different sectors and technologies require different monitoring procedures, the establishment of an overall framework, including assigning responsibility for on-theground monitoring, data storage, information routing, and reporting schedules would streamline the entire process.

\section{Quantify emission reductions: measurement or estimation?}

The city-wide approach presented in this note allows cities the flexibility to use three methods to calculate and aggregate emission reductions for each sector:

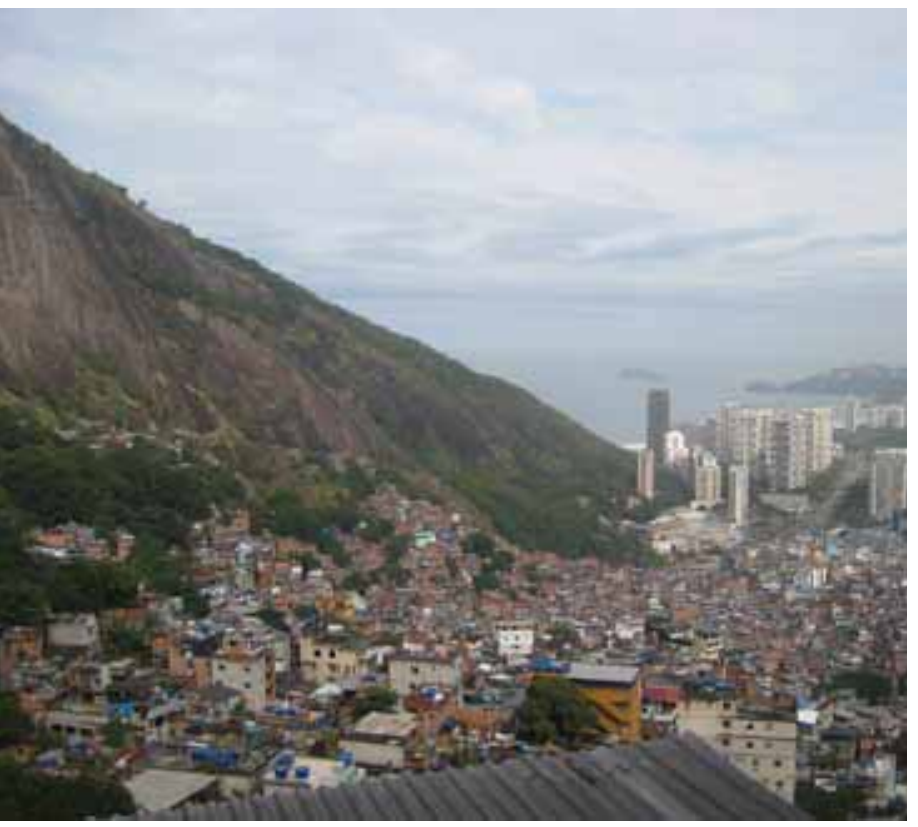

1. 'Measurement'-based approach that involves aggregation of individual interventions using approved CDM methodologies;

2. 'Estimation'-based approach that allows aggregation of activities using energy or GHG intensity-based methodologies. A city may use voluntary carbon market methods or sector-specific common practices to assess GHG reductions in a given sector; and

3. Combined 'measurement' and 'estimation' approach that allows a city to choose between CDM methodologies and other accepted emission estimation methodologies.

The need for an estimation approach arises from: (i) the lack of availability of CDM methodologies to quantify and measure GHG emission reductions from all given interventions in a city; (ii) the excessive requirements for baseline and monitoring assessment required by CDM methodologies; and (iii) the complexity in quantifying emission reductions in a scenario where emissions are significantly increasing. For cities that are growing rapidly, energy intensity indicators may be more appropriate. Generally, industry-specific calculation approaches are available for all interventions and sectors, which can be used instead of the highly complex CDM methodologies. The decision to select one of the three methods depends on the city's capacity to undertake detailed technical analysis and to implement the exact requirements of the CDM methodologies.

It is important to remember that interventions using the 'measurement' approach can already 


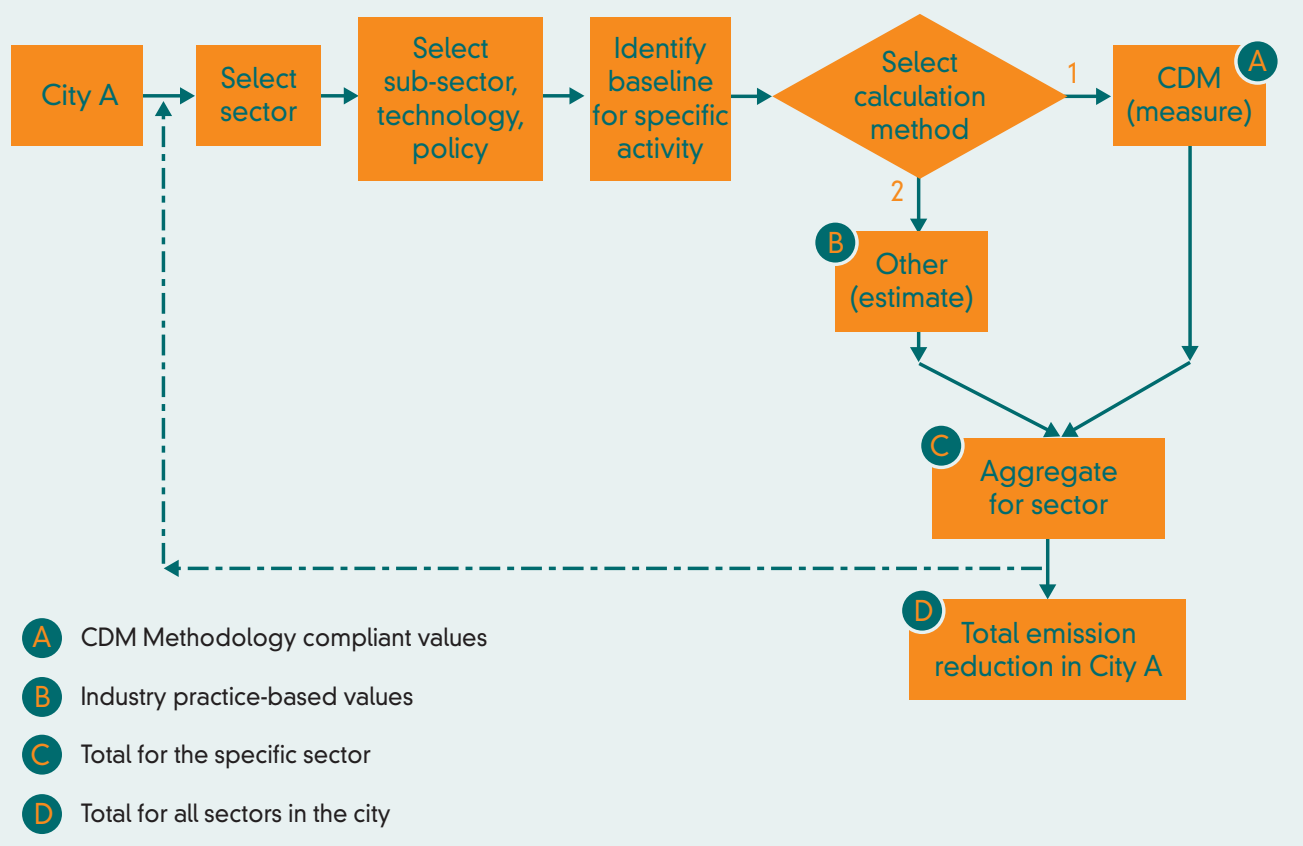

generate emission reduction credits under the CDM as single projects. The 'estimation' approach presented in this document is largely based on energy intensity indicators that are particularly relevant for cities in developing countries given their overall objective of improving and expanding urban services and amenities without limiting their GHG impact on the atmosphere.

\section{Validate and verify ER benefits}

Under the CDM approach for Programmes of Activities, verification of project activities for emission reductions is done at regular intervals, generally on an annual basis, as per the monitoring plan established for the project. The CDM requires a Designated Operational Entity (DOE) to provide thirdparty, independent validation of the project activity and verification of the emission reductions achieved by the activity. The $\mathrm{DOE}$ submits a report to the CDM Board, which leads to the issuance of ERs for trading in the carbon market. The voluntary sector carbon market follows a similar process. If a city decides to undertake the program on its own, it can hire an environmental auditor to verify the emission reductions. 
Cities offer a number of opportunities for GHG mitigation under four broadly categorized sectors: energy, transport, solid waste, and water and wastewater. In addition to these four sectors, which are sources of GHG emissions, urban forestry, as a carbon sink, can also help achieve significant GHG emission reductions. Within these sectors, energy consumption for transportation and in buildings comprises the largest share of emissions - and therefore offers the greatest potential for emission reductions.

The interventions covered in this section to reduce GHG emissions at the city level include technology improvements, e.g., public transportation systems and solar street- lights; policies, such as the implementation of building codes and recycling requirements; and other voluntary actions, including awareness campaigns and recognition programs. For sectors, such as transport, it is important to recognize that a combination of interventions is more successful than individual interventions.

The energy sector in this document is restricted, for simplification, to stationary and mobile combustion activities in a city. Activities under stationary combustion include electricity consumption for provision of urban services as well as residential and non-residential consumers and are covered under the energy sector. Electricity consumption for water supply and wastewater treatment systems is included

\section{Spatial Planning}

A city's spatial development process establishes the location, concentration, distribution, and nature of demand for key urban services, including transport, energy, water, and waste services. It determines the physical and economic constraints and parameters within which infrastructure investments and capacities will need to be designed, and associated costs recovered. Resource efficiency and GHG emissions are directly related to the choice and design of infrastructure systems and service delivery technologies. Good urban planning and spatial development can be thought of as proactive 'demand side' management for resource-efficient infrastructure systems. For instance, public transportation is financially viable only at certain threshold urban densities, and is optimized under certain spatial layouts and land use patterns. At the same time, urbanization downstream from a large water storage facility would likely reduce the need to pump water and construct distribution mains that would be required for more dispersed urbanization upstream from a water facility. In many municipalities, water and wastewater pumping can amount to greater than 30 percent of a city's energy bills.

Source: www.worldbank.org/eco2 
as part of the water and wastewater sector.

Mobile combustion activities restricted to fuel consumption by vehicles are included as part of the transport sector.

Sector-wide and spatial planning approaches, such as integrated waste management or urban densification, could be effective in harnessing local benefits and GHG reduction benefits as part of a single comprehensive intervention. It is important to note that these approaches attempt to incorporate a range of external factors, including economic growth, topography, as well as current land use and it would be a challenge to establish a quantifiable link between the interventions identified during the spatial planning process, their implementation over time and GHG emissions in a city. Integrated approaches are introduced but not elaborated on in this document; however, the city-wide approach is flexible and can incorporate different calculation methodologies.

A city-wide GHG mitigation program would include one or more interventions across one or more sectors over a period of time. As indicated in Figure 7, there are a number of overlaps among the sectors; these should be identified at the time of program development and appropriate adjustments made to the emission reductions estimates to ensure appropriate attribution. The city coordination office would be responsible for ensuring that an activity or its emission reductions are not counted twice. A clear link between activity and impact not only allows
FIGURE 7 Integrated Carbon Finance approach for a City

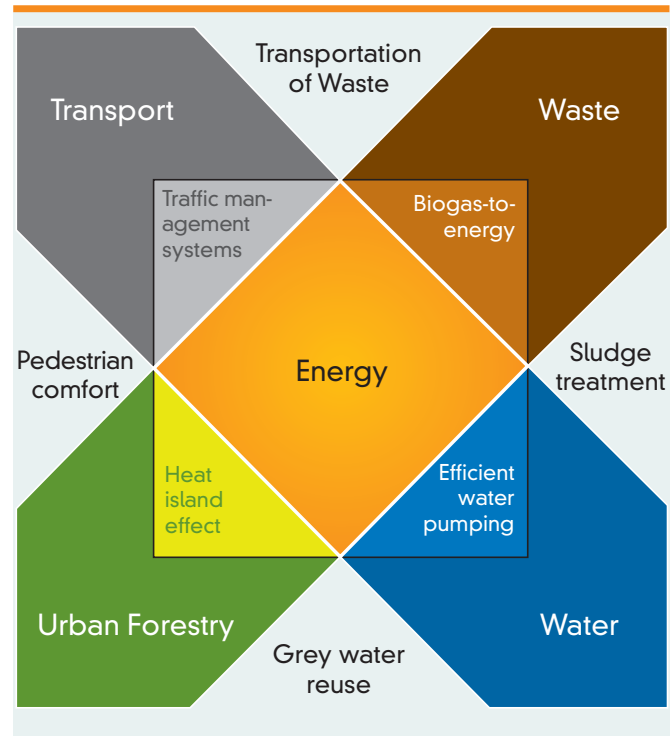

for accurate quantification and monitoring of ERs but also allows carbon incentives to be channeled to the particular activity that has generated them. This section discusses interventions and related local and GHG benefits in the five sectors at city level, with a focus on interventions covered by existing CDM methodologies.

\section{ENERGY}

\section{Overview}

Energy for electricity, heating and cooling buildings, and industrial processes is the biggest source of $\mathrm{CO}_{2}$ emissions globally. The 
IPCC estimates that over 35 percent of global GHG emissions come from energy use (IPCC 2007b). Urban areas currently contribute to 67 percent of the world's energy use. By 2030, this number is expected to rise to 73 percent. As Figure 8 shows, most of this energy comes from coal, oil, and natural gas, which are the main contributors to GHG emissions.

Urban services such as street lighting, water pumping, and public buildings, account for a significant amount of total energy consumption and make up a large portion of a municipality's expenses. While the energy consumption of most urban services comes under the direct control of the city authority, consumption by residential and commercial users is an important component that could be influenced by city governments. The energy

FIGURE 8 Energy demand as a percentage of total energy demand, and related carbon dioxide emissions, 2005 (IPCC 2007c, IEA 2008)

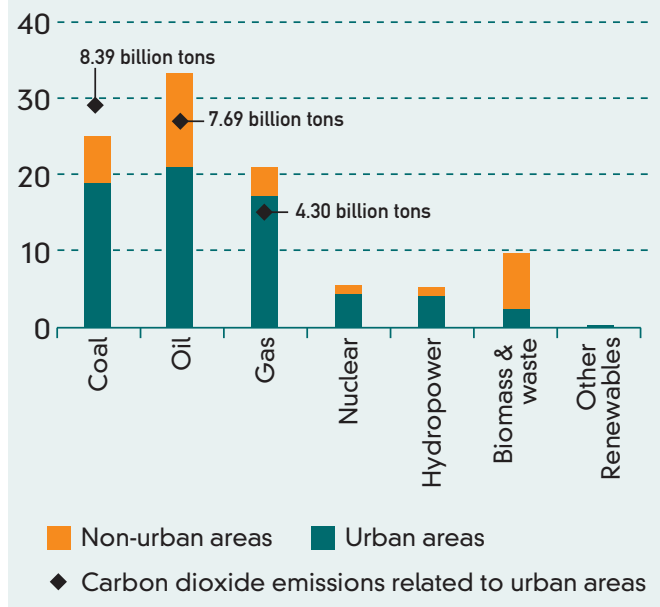

sector is particularly relevant in developing country cities as these cities are expected to increase in population and economic growth in the coming decades. The IEA estimates that in the next two decades energy demand in developing country cities will increase by 81 percent (IEA 2008).

Emission reduction activities primarily fall under two categories: (i) energy efficiency; and (ii) renewable energy. Supply-side energy efficiency includes technological improvements in power plants, combined heat and power (CHP) generation, and transmission and distribution (T\&D) of heat and electricity. Demand-side energy efficiency includes reductions in energy consumption through the provision of urban services as well as public, residential, and commercial buildings and building users. Renewable energy encompasses electricity from 'green' sources such as wind, hydro, or solar. Quantification of emission reductions in the energy sector is based on the assumption that the avoided emissions would have come from an expansion of the existing fossil fuel-based sources of electricity.

Interventions that reduce $\mathrm{GHG}$ emissions also contribute towards broader economic, social, and environmental goals, including reduction in local air pollution, providing better thermal comfort for building users, improving pedestrian safety, reducing expenditure on energy and improved access to energy. The following sub-section provides a brief overview of select interventions. 


\section{Solar Water Heating Program in Rizhao, China (Suzuki et al. 2009)}

Rizhao, an urban area with about 350,000 people in northern China, is using solar energy to provide water, heating, and lighting to its residents. Under a municipal government retrofit program starting in the early 1990 s, the city made it mandatory for all buildings to install solar water heaters. After fifteen years, 99 percent of households in the central district obtained solar water heaters. Solar water heating is now considered common sense. In total, the city has over a half-million $\mathrm{m}^{2}$ of solar water heating panels, the equivalent of around 0.5 MW of electric water heaters. Most traffic signals and street and park lights are powered by solar cells, further reducing the city's GHG emissions and local pollution. This achievement is the result of a convergence of three key factors: a regional government policy that promotes and financially supports the research, development, and deployment of solar water heating technologies; a new industry that has seized available opportunities; and city leadership that not only has a vision but also leads in action and includes stakeholders.

\section{Local and GHG mitigation benefits of interventions}

\section{Buildings}

Buildings are responsible for more than 30 percent of the total energy consumption globally and provide the largest opportunity in improving demand-side energy efficiency. Buildings have a long lifetime and once constructed result in a lock-in of the design and technical characteristics for many decades. New buildings provide multiple opportunities to reduce energy consumption through energy embedded in construction materials, building design, equipment and appliances, and building use. For example, designing a building at a site with appropriate physical orientation could allow for day-lighting and thermal characteristics which can significantly reduce energy demand for the users. Integration of renewable energy sources, solar water heating, lighting and cooling, centralized airconditioning, and the use of energy efficient equipment, such as chillers and refrigerators can provide significant energy savings. Retrofit and refurbishment of existing buildings also provide significant opportunities to reduce energy use.

City authorities can play an important role in the establishment and implementation of building energy efficiency codes. Mandatory implementation of these codes itself could lead to reductions in energy consumption by $20-50$ percent. Cities are also best placed to provide information and create awareness regarding energy efficiency among building users. Direct local benefits of efficient buildings include reduced energy consumption, a corresponding 
reduction in energy bills, as well as superior user comfort in terms of lighting, thermal comfort, and usability.

Quantification of energy savings and GHG benefits of building energy efficiency improvements is challenging as it is highly dependent on consumer behavior and is also affected by the interaction of different components, e.g., the orientation and size of windows affects the amount of electricity needed for air-conditioning and lighting. Existing CDM methodologies calculate energy savings in buildings by each component. The building simulation approach used by experts in this sector provides the required 'wholebuilding' approach to assess energy savings. A new CDM methodology is being developed using this approach to estimate and verify energy savings from buildings.

\section{Street lighting}

Streetlights are an important public service as they improve public safety and mobility after sunset. Streetlights in developing country cities are often old or inefficient; however, due to competing city priorities, they continue to operate inefficiently until they reach their end of life. Most streetlights operate for 9 to 12 hours every night, depending on the season. Typically, bulbs or tubular streetlights last a year whereas fixtures can last for as long as 10 or more years with requisite maintenance, although with diminishing efficiency levels.

Several technological improvement options exist for streetlights, including improved fixtures

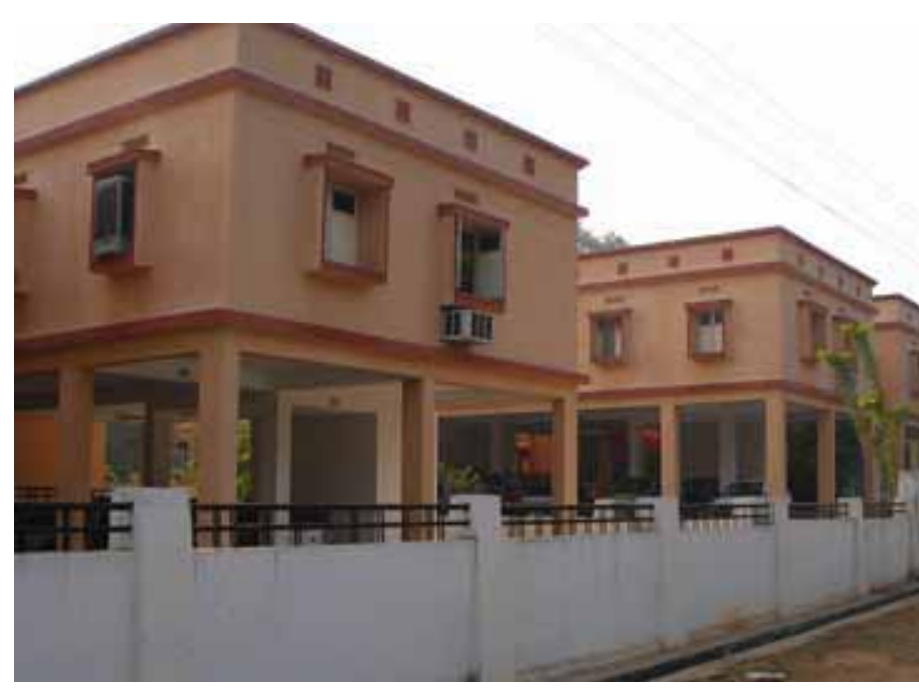

(e.g., electronic ballasts), high efficiency lights (e.g., LEDs), and the use of solar photovoltaic technology. In addition, advanced centralized street lighting control systems enable municipalities to better control their operations and costs. Similar technological interventions can be used for traffic lights and other public lighting requirements, including bus stations, recreational areas, and security/peripheral lights.

Calculation of energy savings and emission reduction benefits for higher efficiency streetlights is relatively easy as it only requires a comparison between the energy consumption of different technologies while maintaining or improving the quality of lighting. This intervention is covered by a CDM methodology, as shown in Table 2.

\section{District heating}

District heating (DH) systems distribute steam or hot water to multiple buildings over 


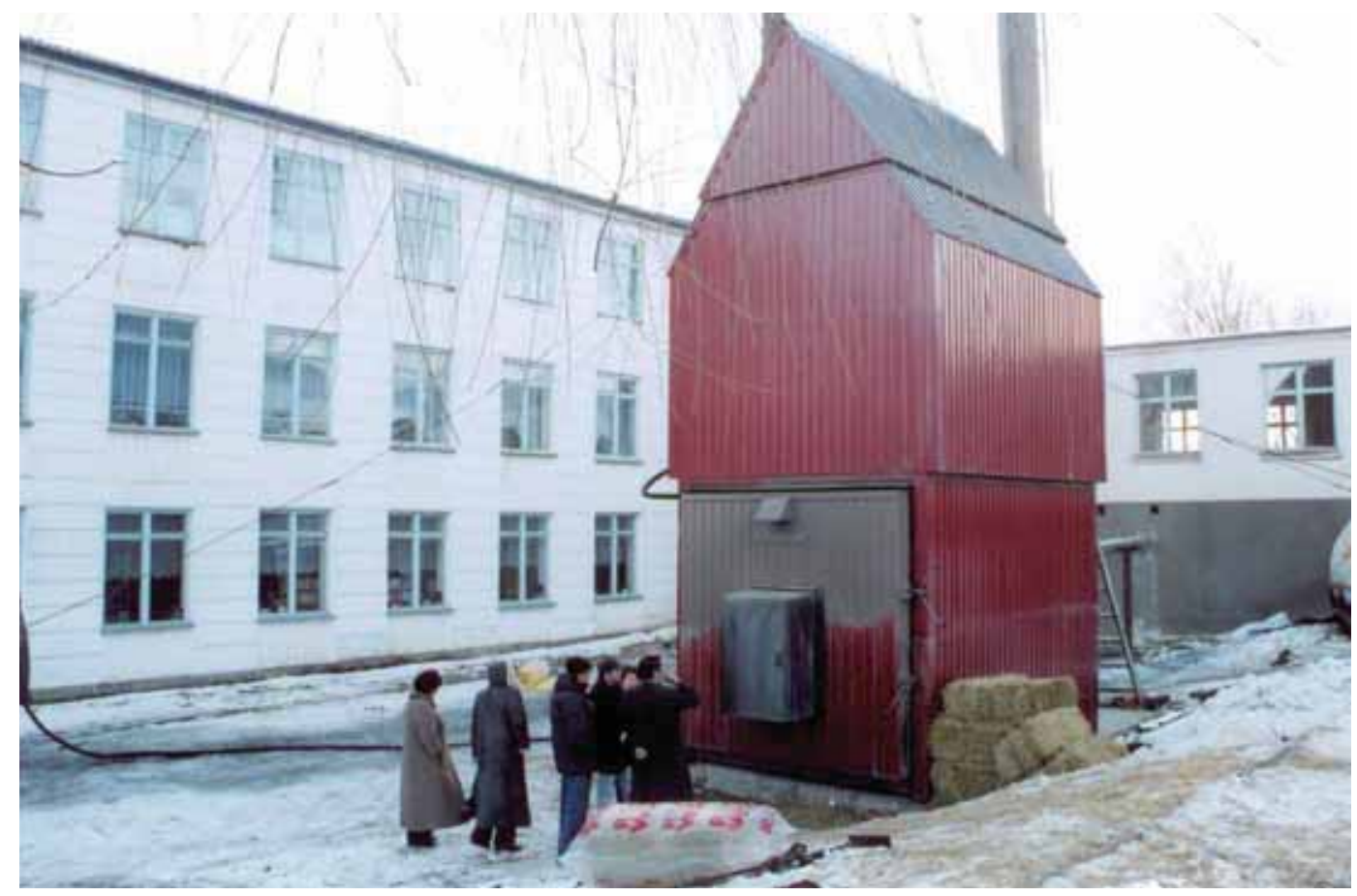

large areas. This heat can be obtained from a variety of sources, including power plants, cogeneration plants, waste heat from industrial activities, purpose-built heating plants, and renewable sources such as geothermal energy. Buildings that are part of a district heating system do not require their own boilers, furnaces, chillers, or air-conditioners.

A city can undertake the installation of a high efficiency new district heating system or reduce emissions from an existing system. Reductions in emissions from existing systems can come from switching from fossil fuels to renewable sources, including biomass and geothermal, and improving efficiency in power or co-generation plants. Existing systems can also improve efficiency by (i) switching from group substations, which serve a number of buildings, to building-level sub-stations; (ii) replacing old individual inefficient boiler units with a centralized DH system; and (iii) advanced heat control systems. This reduces electricity used for pumping and fuel used for heating, thus enabling optimization of heat demand. To further improve efficiency of a DH system, a cascade heating system can be designed, which further reduces return temperature of the water by utilizing it for low-temperature heating systems (e.g., floor heating) before returning it to the plant.

An energy efficient and viable option for cooling is the utilization of hot water from a 
DH system as an energy source for absorption chillers. Such a system could either be centralized by producing cooling in the CHP plant or decentralized by installing chillers at the end-user facility. An additional benefit of such a cooling system would be reduced electricity demand peaks in summer time and substantial reductions in energy consumption. Interventions involving existing and new district heating systems are covered by CDM methodologies, which are listed in Table 2.

\section{Electricity from renewable energy sources}

Many cities can access large renewable energy sources for power generation. These include biomass-based CHP, wind, or geothermal power plants. Cities that do not have direct access to these sources can purchase 'green' electricity through power utilities. While this intervention does not provide immediate local economic or environmental benefits, it does contribute to reduced pollution due to fossilfuel based power generation and in case of dispersed small renewable power systems, e.g., solar home lighting systems or solar water heating, it will improve air quality due to avoidance of small and mostly inefficient fossil-fuel based energy systems, e.g., kerosene lamps and diesel generators.

\section{Policy and other interventions}

Many cities have green building incentive programs that reward building owners for reductions in embedded energy (e.g., switching to environmentally-friendly construction materials) and for reduced energy
The American Council for an Energy

Efficient Economy (ACEEE) estimates that around 25 percent of total energy demand could be eliminated through behaviorbased energy efficiency improvements.

Efficiency 2.0, Behavior as a Resource

consumption (e.g., more efficient electrical equipment). Minimum energy efficiency performance standards for lighting devices, major appliances, office equipment, and other important energy-consuming equipment are generally set at a national level; however, these standards can be promoted through interventions at the city level to encourage the use of high-efficiency equipment.

Procurement norms and standards for equipment purchase by city authorities are a major barrier to improving the city's own operations. Most developing country cities follow strict guidelines, which currently do not incorporate energy savings or life-cycle costing, consequently impeding the purchase of high-efficiency, high-cost equipment. Capacity building and awareness campaigns have successfully promoted demand-side energy efficiency and use of renewable energy around the world. Such campaigns are run either by city authorities themselves, local utilities, educational institutions, or NGOs. CDM methodologies do not cover many of these policy-level interventions; however, if clear indicators linking policy implementation with consumer activity can be established, 
TABLE 2 Energy sector interventions, benefits, and quantification methods

\begin{tabular}{|c|c|c|c|}
\hline \multirow[b]{2}{*}{ Technology/Intervention } & \multirow[b]{2}{*}{ Direct Local Benefits } & \multicolumn{2}{|c|}{ GHG Quantification Approach } \\
\hline & & $\begin{array}{l}\text { CDM } \\
\text { Methodology }\end{array}$ & $\begin{array}{l}\text { Indicator for } \\
\text { Estimation }\end{array}$ \\
\hline \multicolumn{4}{|l|}{ Energy efficiency (demand-side) } \\
\hline Efficient street lighting & $\begin{array}{l}\text { Resident safety, traffic } \\
\text { convenience }\end{array}$ & AMS II.C & $\begin{array}{l}\mathrm{kWh} / \mathrm{km} \text { of } \\
\text { street-light }\end{array}$ \\
\hline $\begin{array}{l}\text { Buildings energy efficiency \& renewable } \\
\text { energy }\end{array}$ & \multirow[t]{2}{*}{$\begin{array}{l}\text { User comfort and } \\
\text { aesthetics }\end{array}$} & AMS III.AE & \multirow[t]{2}{*}{$\mathrm{W} / \mathrm{m}^{2}$} \\
\hline $\begin{array}{l}\text { Whole building efficiency improvements } \\
\text { (envelope, lighting, heating and cooling) }\end{array}$ & & & \\
\hline Efficient electrical equipment (refrigeration) & \multirow{2}{*}{$\begin{array}{l}\text { User comfort and } \\
\text { potential avoidance of } \\
\text { non-GHG gases }\end{array}$} & AM0060 & $\mathrm{kW} / \mathrm{TR}$ \\
\hline $\begin{array}{l}\text { Efficient electrical equipment } \\
\text { (e.g., lights, air-conditioners) }\end{array}$ & & AMS II.C, AMS II.J & $\mathrm{kW} /$ lumen \\
\hline
\end{tabular}

\begin{tabular}{|c|c|c|c|}
\hline \multicolumn{4}{|l|}{ Energy efficiency (supply-side) } \\
\hline $\begin{array}{l}\text { Efficiency improvements in power supply } \\
\text { (e.g., loss reduction in T\&D, transformers) }\end{array}$ & $\begin{array}{l}\text { Better quality of power } \\
\text { supply }\end{array}$ & $\begin{array}{l}\text { AMS II.A } \\
\text { AM0067 }\end{array}$ & $\begin{array}{l}\% \\
\text { improvement }\end{array}$ \\
\hline $\begin{array}{l}\text { Efficiency improvements in district heating } \\
\text { and co-generation facilities }\end{array}$ & \multirow[t]{2}{*}{ User comfort } & $\begin{array}{l}\text { AMS II.B } \\
\text { AM0044 }\end{array}$ & $\mathrm{kJ} / \mathrm{km}, \mathrm{kJ} / \mathrm{unit}$ \\
\hline New district heating networks & & AM0058 & $\mathrm{kJ} / \mathrm{unit}$ - fuel \\
\hline Efficiency improvements in power plants & $\begin{array}{l}\text { Local environmental } \\
\text { benefits of avoided new } \\
\text { coal plants }\end{array}$ & AM0061, 62 & $\mathrm{~kJ} / \mathrm{unit}$ \\
\hline \multicolumn{4}{|l|}{ Renewable Energy } \\
\hline Electricity from renewable sources & $\begin{array}{l}\text { Local environment } \\
\text { benefits of avoided new } \\
\text { coal plants }\end{array}$ & $\begin{array}{l}\text { ACM0002 } \\
\text { AMS I.D }\end{array}$ & kWh \\
\hline Solar water heating & $\begin{array}{l}\text { User comfort and self- } \\
\text { reliance }\end{array}$ & AMS I.C & $\mathrm{kWh} / \mathrm{m}^{3}$ \\
\hline Solar lighting in streets and households & \multirow{2}{*}{$\begin{array}{l}\text { Reduced dependence on } \\
\text { grid power }\end{array}$} & AMS I.A & $\mathrm{kWh} / \mathrm{km}$ \\
\hline Heat pumps for heating and cooling & & $\begin{array}{l}\text { AM0072 } \\
\text { AMS I.C }\end{array}$ & $\mathrm{kWh} / \mathrm{m}^{2}$ \\
\hline
\end{tabular}

For questions, inputs, suggestions, contact: mranadeđaworldbank.org; hgaddeßaworldbank.org

e.g., awareness campaigns that result in a corresponding increase in the purchase of high-efficiency equipment, energy savings can be attributed to the policy intervention. It is important to note that this is not a widely accepted approach in CDM. 


\section{TRANSPORT}

\section{Overview}

Thirteen percent of global greenhouse gas emissions come from transportation (or 25 percent, when excluding emissions from deforestation) (IPCC 2007a). The transport sector, particularly in developing countries, plays a critical role in greenhouse gas emissions reduction schemes, not only because emissions from this sector comprise a significant portion of global emissions today, but also because without preventive action, transport sector emissions are expected to increase exponentially in developing countries.

Taking pre-emptive steps towards emissions reductions in the transport sector is particularly critical, because the costs of future retroactive mitigation activities may be prohibitive. Transport sector improvements are resourceintensive and are very difficult to "undo."To illustrate, once road, rail, and water networks are established and entire communities and local economies grow in synergy around them (e.g., US suburban sprawl that is dependent on its highway system), retroactively re-planning employment and population centers, fueling infrastructure, and modes of travel can be a tremendous undertaking.

Fortunately, programs and activities that reduce greenhouse gas emissions in the urban transport sector will usually meet broader economic, social, and environmental goals than just climate change mitigation. This is because actions that reduce greenhouse gas emissions in the transport sector do so by:

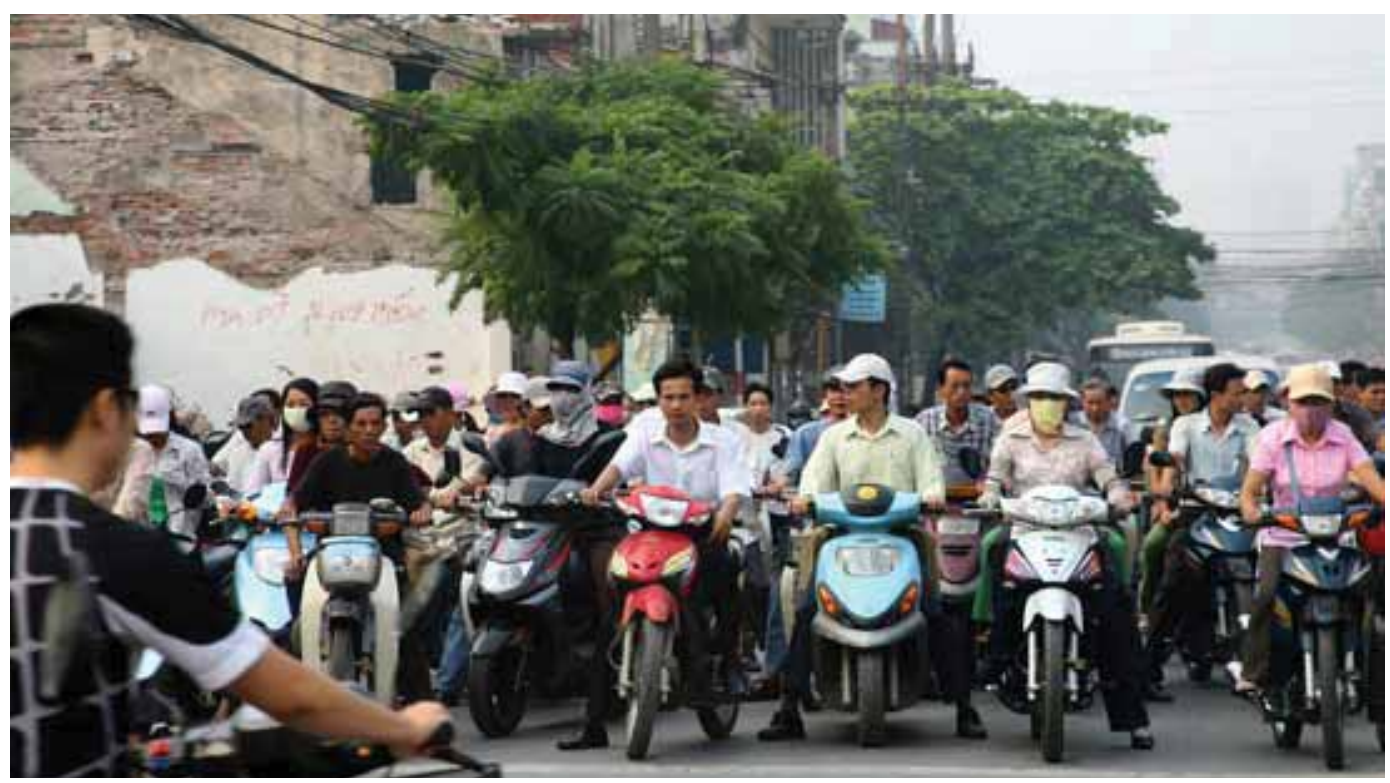




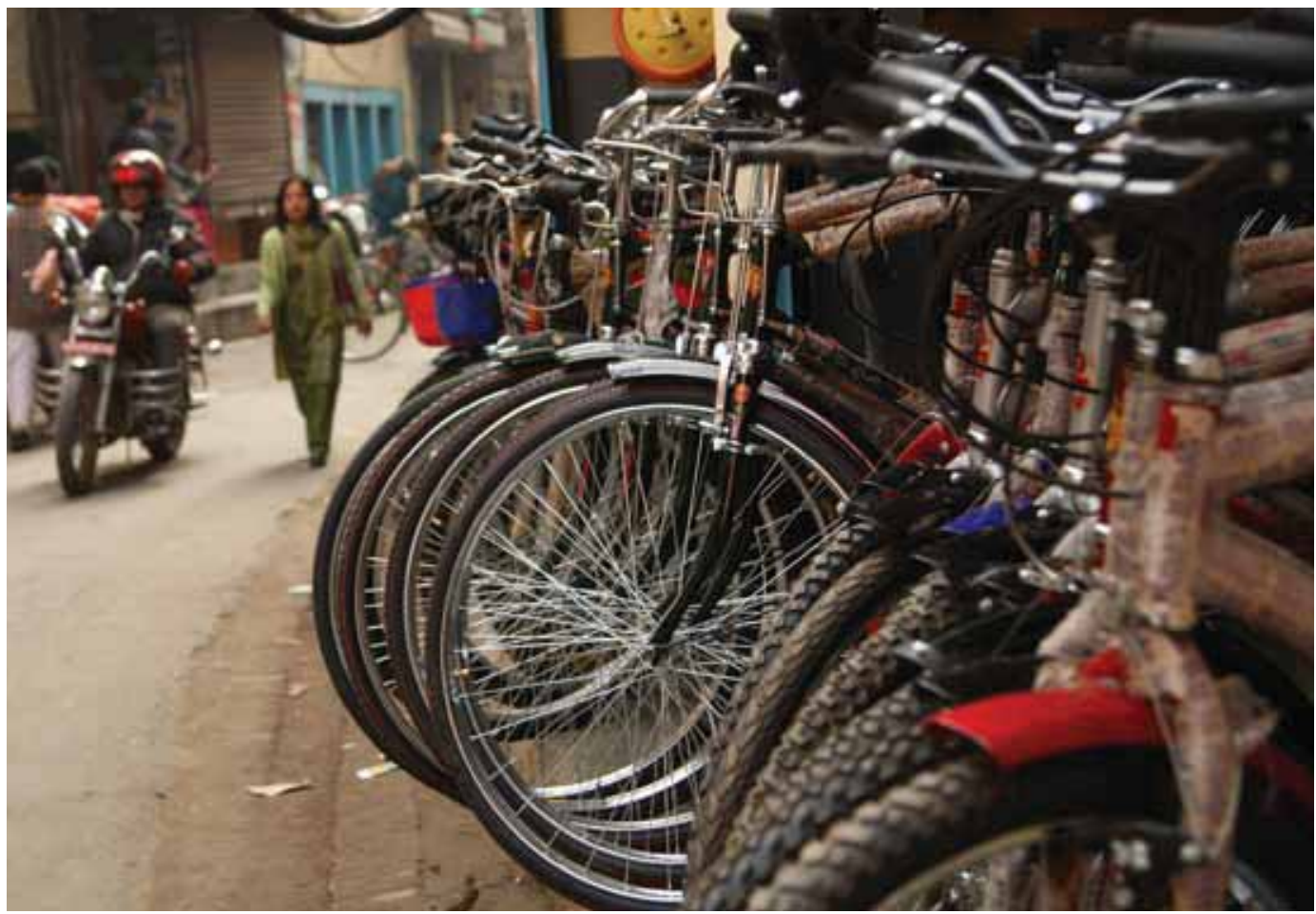

- Utilizing lower carbon-content fuels (which tend to generate less air pollution);

- Improving energy efficiency (which tends to reduce costs); or

- Optimizing vehicle distance traveled (e.g., mass transit promotion, fleet route optimization-which tend to reduce congestion and improve travel times).

Many goals that planners and engineers have for improvement in transport systems - congestion reduction, travel time improvement, promotion of non-motorized transport, air pollution mitigation, etc.are met through these activities that will also reduce emissions.

\section{Local and GHG mitigation benefits} of interventions

Thousands of activities can be undertaken to improve the performance of the urban transport sector. The challenge for planners and policymakers is to determine which of these activities could also lead to a direct impact on GHG emissions. As a general rule of thumb, most activities that reduce emissions from the transportation sector will fall into one or more of three overarching strategies:

- Reduce emissions per kilogram of fuel combusted (e.g., ton $\mathrm{CO}_{2} \mathrm{e} / \mathrm{kg}$ ); 
- Reduce fuel combusted per kilometer traveled (e.g., kg/km); or

- Reduce vehicle kilometers traveled $(\mathrm{km})$.

\section{Emissions per kilogram of fuel combusted}

Most greenhouse gas emissions from the transport sector stem from the combustion of fossil fuels, whether in the form of a mobile source fuel (e.g., gasoline, diesel, CNG) or electricity (e.g., coal, natural gas). By selecting fuels that emit fewer GHG per kilogram of fuel combusted (e.g., $\mathrm{tCO}_{2} \mathrm{e} / \mathrm{kg}$ ), overall greenhouse gas emissions can be reduced. As an additional benefit, some lower carbon fuels also have fewer pollutants (e.g., carbon monoxide and particulate matter) and can mitigate air pollution.

\section{Fuel combusted per kilometer traveled}

Strategies that reduce fuel combusted per vehicle-kilometer (e.g., $\mathrm{kg} / \mathrm{km}$ ) usually include the implementation of vehicle technologies that improve energy efficiency (e.g., procurement of vehicles with more fuel efficient engines, installation of antiidling technologies, low-emission tires) and implementation of policy measures that improve overall energy efficiency (e.g., development of driver improvement courses, road maintenance programs, congestion mitigation programs). Improving fuel efficiency not only helps mitigate air pollution, but also lowers vehicle operating costs and, in some cases, dependency on imported fuels.

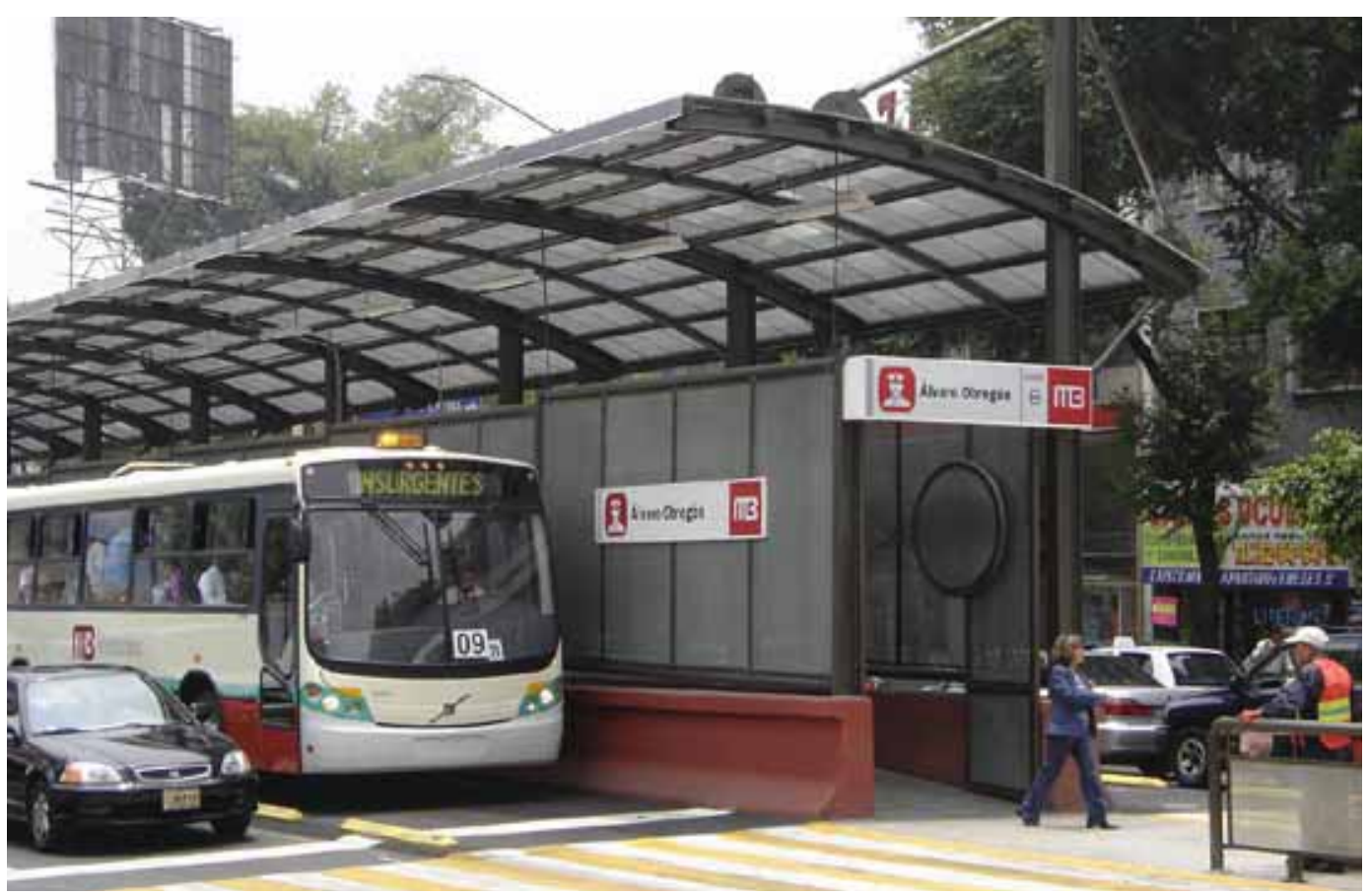




\section{Vehicle kilometers traveled}

By reducing overall vehicle kilometers traveled (VKT), cities can reduce the total amount of fuel consumed, and therefore reduce overall greenhouse gas emissions as well as air pollution and congestion. Most measures that reduce VKT are more "policy"-focused than "technology"-focused. For example, measures that reduce overall VKT may include congestion charging, vehicle registration quotas, or telecommuting incentive schemes. These strategies can have a wide range of benefits-improved air quality, reductions in congestion and system-wide travel times, and improved safety and conditions for nonmotorized transport.

Figure 9 provides examples of each of the strategies in the form of an equation, which shows how reductions in tons of greenhouse gas emitted per unit of combusted fuel, reductions in fuel combusted per kilometer traveled, and/or overall vehicle activity would reduce overall emissions relative to what they would have been in absence of the activity.

Most urban transport programs will incorporate a combination of these strategies. For example, a bus rapid transit (BRT) scheme may include:

- A switch from diesel to CNG hybrid vehicles (reduce $\mathrm{tCO}_{2} \mathrm{e} / \mathrm{kg}$ );

- Improved vehicle fuel efficiency, smoother driving surfaces, less idling, and better driver performance (reduce $\mathrm{kg} / \mathrm{km}$ ); and

- A net modal shift from private vehicles to transit (reduce overall vehicle-km-traveled).

FIGURE 9 Illustration of interventions in the urban transport sector

Reduce $\mathrm{CO}_{2} \mathrm{e}$
emissions per kg
fuel combusted
Switch to low-
carbon fuels
Switch to electricity

- Switch to electricity

Reduce fuel
combusted per
km traveled
High fuel economy
vehicles
- Engine maintenance
- Operations
improvements
- Anti-idling measures
- Improved driving
surfaces
- Congestion relief
Replacement
standards

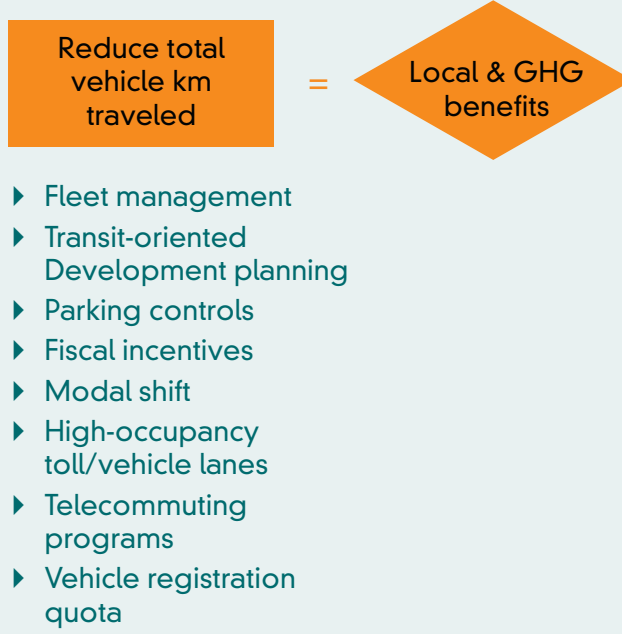


TABLE 3 Transport sector interventions, benefits, and quantification methods

\begin{tabular}{|c|c|c|c|}
\hline \multirow[b]{2}{*}{$\begin{array}{l}\text { Technology/ } \\
\text { Intervention }\end{array}$} & \multirow[b]{2}{*}{$\begin{array}{l}\text { Direct Local } \\
\text { Benefits }\end{array}$} & \multicolumn{2}{|c|}{ GHG Quantification Approach } \\
\hline & & $\begin{array}{l}\text { CDM } \\
\text { Methodology }\end{array}$ & $\begin{array}{l}\text { Indicator for } \\
\text { Estimation }\end{array}$ \\
\hline \multicolumn{4}{|c|}{ Reduced vehicle-kilometers traveled } \\
\hline $\begin{array}{l}\text { Mass rapid transit } \\
\text { (no feeders) }\end{array}$ & \multirow[t]{3}{*}{$\begin{array}{l}\text { Air quality, safety, } \\
\text { travel time savings }\end{array}$} & AM0016 & \multirow[t]{3}{*}{$\begin{array}{l}\mathrm{tCO}_{2} \mathrm{e} / \mathrm{unit} \text { fuel; } \\
\text { unit fuel/km; km }\end{array}$} \\
\hline $\begin{array}{l}\text { Bus rapid transit } \\
\text { (with feeders) }\end{array}$ & & AM0031 & \\
\hline Cable cars & & AMS IIIU & \\
\hline \multicolumn{4}{|l|}{ Lower carbon content of fuel } \\
\hline Bio-diesel & \multirow[t]{3}{*}{ Air quality } & ACM0017 & $\mathrm{tCO}_{2} \mathrm{e} /$ unit fuel \\
\hline Plant oil production and use & & AMS IIIT & $\mathrm{tCO}_{2} \mathrm{e} /$ unit fuel \\
\hline $\begin{array}{l}\text { Grid-connected renewable energy } \\
\text { for vehicles }\end{array}$ & & AMS ID + AM0019 & \\
\hline \multicolumn{4}{|c|}{ Reduced average fuel combusted per vehicle-kilometer travelled } \\
\hline Vehicle retrofits & Air quality & AMS IIIAA & $\begin{array}{l}\mathrm{tCO}_{2} \mathrm{e} / \mathrm{kWh} \\
\text { tons }\end{array}$ \\
\hline Low emissions vehicles & & $\begin{array}{l}\text { AMS IIIC, } \\
\text { AMS IIIS }\end{array}$ & Unit fuel $/ \mathrm{km}$ \\
\hline
\end{tabular}

For questions, inputs, suggestions, contact: hkrambecklaworldbank.org

It should be noted that these activities are a general guide to help urban planners and policy makers identify opportunities for reducing greenhouse gas emissions in the transport sector. It should be mentioned, though, that some activities that reduce greenhouse gas emissions directly may also encompass rebound effects or "leakage" emissions that offset the emission reduction benefits. For example, the allocation of existing road space to a dedicated bus lane may induce a modal shift to buses, which would result in more efficient passenger transport than with low-occupancy modes, but on the other hand, the reduction in road space for other vehicles may increase congestion and idling, reducing the fuel efficiency (fuel combusted per kilometer traveled) of the vehicles on that corridor. For most projects or programs seeking carbon finance resources, these rebound and leakage issues are explored. 


\section{SOLID WASTE}

\section{Overview}

The solid waste sector contributes to greenhouse gas emissions primarily through the generation of methane from landfills as well as minor amounts of $\mathrm{CO}_{2}$ through incineration. Three percent of global GHG emissions come from solid waste and wastewater treatment (IPCC 2007a), most of which can be attributed to urban areas. Although this may seem like a tiny fraction of

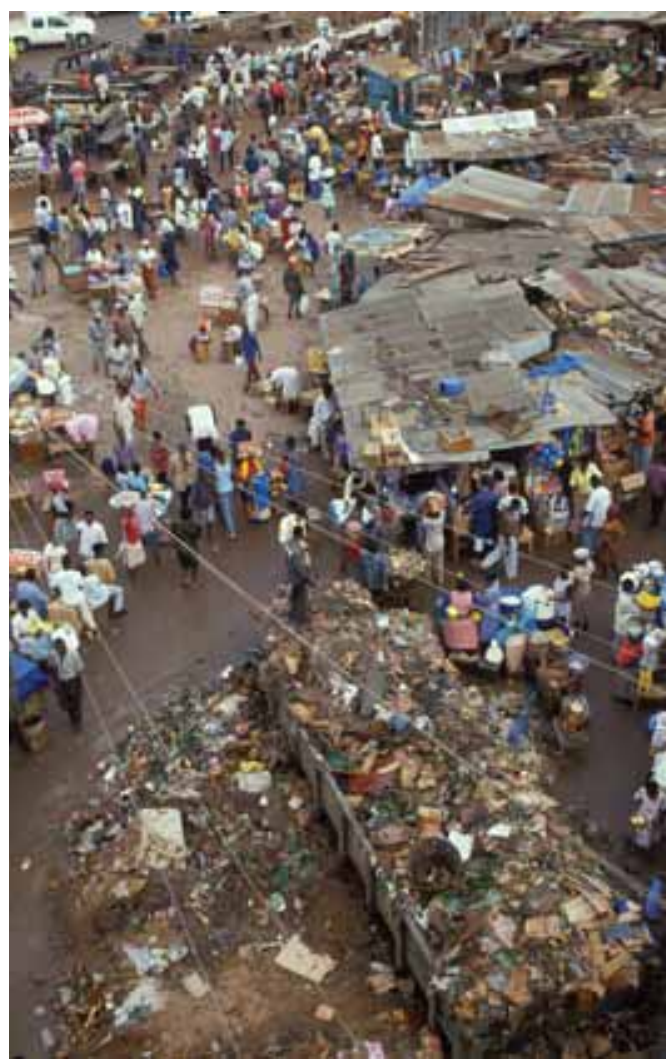

global emissions, it is equivalent to 1.32 billion tons of $\mathrm{CO}_{2} \mathrm{e}$, which provides significant $\mathrm{GHG}$ mitigation opportunities.

Solid waste generation is essentially considered to be an urban problem as city residents generally have more disposable income to spend on consumer goods and services, thus increasing the amount of solid waste generated. In Thailand, for example, metropolitan Bangkok has twice the national average rate of waste generation (Hiramatsu et al. 2009). Waste generation is also directly linked to economic growth. As developing countries grow and urbanize, the amount of waste generated is expected to increase. Thus, GHG emissions associated with waste management is an area that is receiving increasing attention as concerns grow about the effect of climate change on the global environment.

A well-functioning municipal solid waste (MSW) management sector is a critical element of urban life. Protection of the environment, improved public health, aesthetics, and better city finances are products of a properly designed and operated waste management system.

Although municipal waste accounts for a small fraction of global GHG emissions with the largest contributor being methane from waste disposal, in landfills for example, methane from landfills represents 12 percent of total global methane emissions.

The GHG effect of waste management can be reduced and it has even been forecasted 
that waste management in some locations can become a net saver of GHG emissions. Within the European Union, the rate of GHG emissions from solid waste has declined from 69 million $\mathrm{tCO}_{2}$ e to 32 million $\mathrm{tCO}_{2}$ e from 1990 to 2007 (ISWA 2009).

\section{Local and GHG mitigation benefits of interventions}

The elements of the waste management sector in the generally accepted hierarchy of preference from an environmental perspective and the associated GHG emissions are summarized in Figure 10. Interventions in the solid waste management sector offer a number of direct local benefits in the form of reduced costs for packaging and waste collection, lower amounts of waste produced, improved public health, lower air pollution, and overall improvements in the environment. Interventions to reduce greenhouse gas emissions associated with waste management, with approved CDM methodologies that can generate a cash flow of revenue for the GHG emission reductions achieved are listed in Table 4.

\section{Waste reduction}

Waste or source reduction initiatives seek to reduce the quantity and/or toxicity of waste at generation points by redesigning products or changing patterns of production and consumption. A reduction in waste generation has a two-fold benefit in terms of GHG emission reductions: (i) emissions associated with material and product manufacture are avoided; and (ii) there are no GHG emissions due to waste management.

\section{Waste collection}

Trucks typically collect and transport municipal waste and recyclables to a treatment or disposal facility. Depending on the distance waste needs to be transported, cities may use a transfer station where waste from several routes is consolidated into larger trucks for transport to distant treatment facilities or landfills (minimum 25 to $40 \mathrm{~km}$, depending on travel time). $\mathrm{GHG}$ emissions occur through $\mathrm{CO}_{2}$ from fossil fuel consumption during operation of collection vehicles for waste or sourceseparated recyclables.

FIGURE 10 Hierarchy of policy options (Peterson 2009)

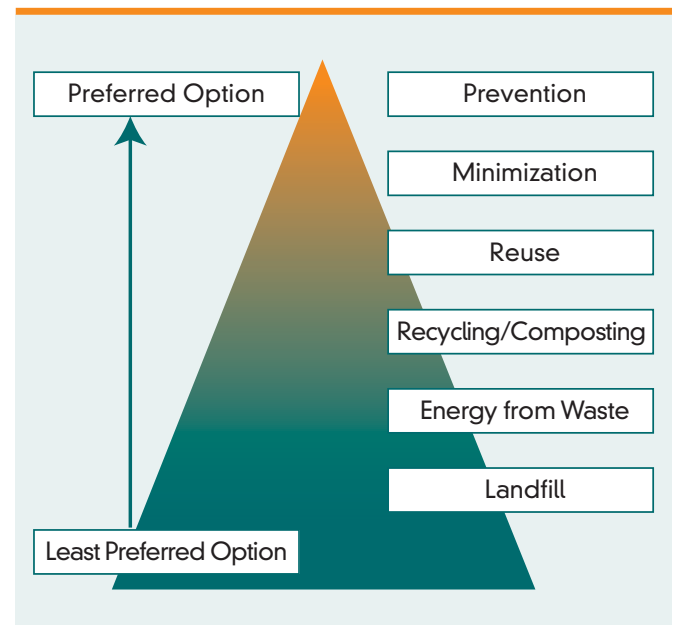

\section{Recycling/materials recovery}

The key advantages of recycling and recovery are that they reduce the amount of waste 
disposed and increase the return of materials to the economy. In many developing countries, informal waste pickers at collection points and disposal sites recover a significant portion of discards. In China, for example, about 20 percent of discards are recovered for recycling, largely attributable to informal waste picking (Hoornweg et al. 2005). Related GHG emissions come from operation of material recovery facilities. Informal recycling by waste pickers will have little GHG emissions, except for processing the materials for sale or reuse.

\section{Aerobic composting/anaerobic digestion}

Composting with windrows or enclosed vessels is intended to be an aerobic operation that avoids the formation of methane associated with anaerobic conditions (in the absence of oxygen). When using an anaerobic digestion process, organic waste is treated in an enclosed vessel. Often associated with wastewater treatment facilities, anaerobic digestion will

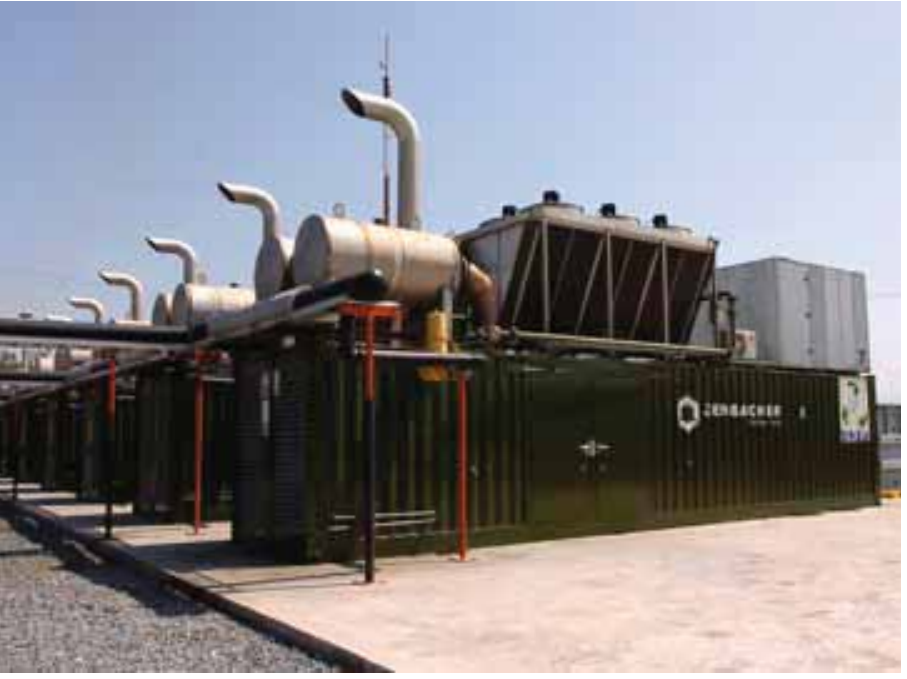

result in methane that can either be flared or used to generate electricity. GHG emissions occur from consumption of electricity to power the equipment. Additionally, methane and nitrous oxide may be generated with improperly operated composting systems. Methane is an intended product of anaerobic digestion that can easily be captured and treated in an enclosed vessel.

\section{Incineration/waste-to-energy}

Incineration of waste with or without energy recovery measures can reduce the volume of disposed waste by 90 percent. Volume is a more important measure than weight in assessing the demand on landfills. GHG emissions come from consumption of fossil fuel or electricity to power equipment. Emissions also come from combustion of fossil fuel-based waste such as plastics and textiles; however, these emissions are minor compared to that from landfills. Estimated GHG emissions from waste are less than one-tenth that of landfills (IPCC 2007d). Emissions from organic biomass (paper, food) are classified as biogenic, natural source of emissions and not counted as anthropogenic emissions.

\section{Landfills}

The waste or residue from other processes should be sent to a disposal site. Landfills, a common last disposal site for waste, should be engineered and operated to protect environmental and public health. Methane from decomposition of organic waste under anaerobic conditions and $\mathrm{CO}_{2}$ 


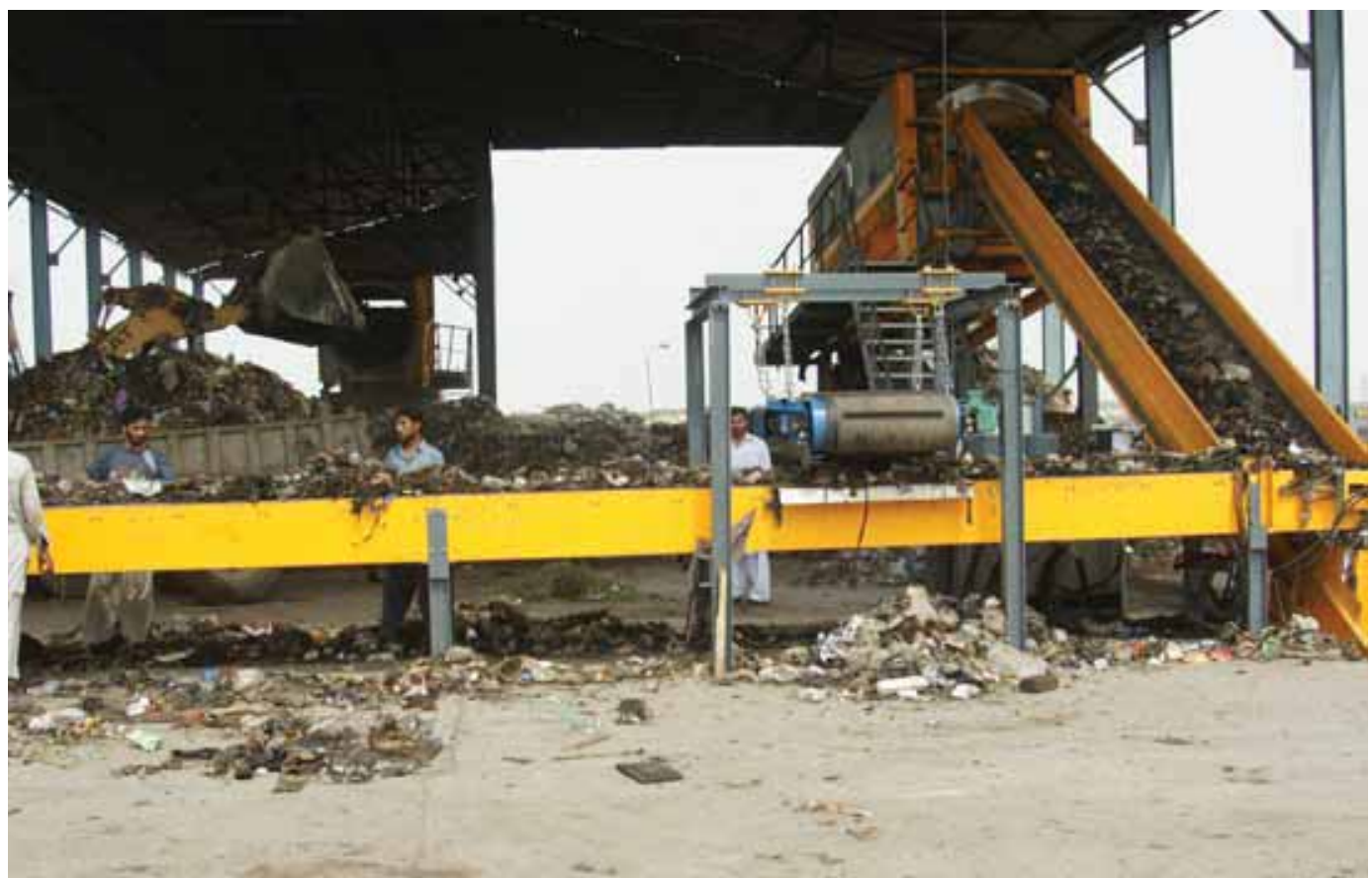

from consumption of fossil fuels to power equipment constitute the GHG emissions from landfills.

\section{Policy options}

Governments have a range of policy options to stimulate waste management practices that will result in lower levels of GHG emissions. Public education would inform people about their options to reduce waste generation and increase recycling and composting, particularly in urban areas with single family housing. These are areas in which individuals can have a direct effect on the reduction of GHG emissions. Preferential procurement policies and pricing could stimulate demand for products made from recycled post-consumer discards including use of compost in public parks and other property owned by cities.

Pricing mechanisms such as product charges, can stimulate consumer behavior to reduce waste generation and/or increase recycling. A product charge is a cost assessment added to the price of a product and is tied to the cost of a desired waste management system. Consumers would pay for the waste management service when they buy a product. The fees collected would be directed to municipalities commensurate with the waste generated. An excise tax on tires assessed by most states in the United States is an example of this economic mechanism (Peterson 1979). However, product charges are a policy 
TABLE 4 Solid waste sector interventions, benefits, and quantification methods

\begin{tabular}{|c|c|c|c|}
\hline \multirow[b]{2}{*}{$\begin{array}{l}\text { Technology/ } \\
\text { Intervention }\end{array}$} & \multirow[b]{2}{*}{ Direct Local Benefits } & \multicolumn{2}{|c|}{ GHG Quantification Approach } \\
\hline & & $\begin{array}{l}\text { CDM } \\
\text { Methodology }\end{array}$ & $\begin{array}{l}\text { Indicator for } \\
\text { Estimation }\end{array}$ \\
\hline $\begin{array}{l}\text { Aerobic composting, } \\
\text { anaerobic digestion, } \\
\text { refuse derived fuel, or } \\
\text { incineration }\end{array}$ & $\begin{array}{l}\text { Avoided waste disposal } \\
\text { of organic biomass that } \\
\text { contributes to public health } \\
\text { and environmental effects of } \\
\text { disposal; except for composting, } \\
\text { contributes to renewable energy } \\
\text { supply }\end{array}$ & $\begin{array}{l}\text { AM0025, } \\
\text { AMS III.E } \\
\text { AMS-III.F }\end{array}$ & $\mathrm{CH}_{4} / \mathrm{kg}$ (IPCC 2006) \\
\hline $\begin{array}{l}\text { Methane avoidance by } \\
\text { in-situ treatment of } \\
\text { anaerobic conditions in } \\
\text { a landfill }\end{array}$ & $\begin{array}{l}\text { Contributes to better operated } \\
\text { landfill reducing public health } \\
\text { and environmental effects of } \\
\text { standard landfill }\end{array}$ & $\begin{array}{l}\text { AM0083, } \\
\text { AMS III.AF }\end{array}$ & $\mathrm{CH}_{4} / \mathrm{kg}(\mathrm{IPCC} 2006)$ \\
\hline $\begin{array}{l}\text { Landfill gas capture/ } \\
\text { treatment/use }\end{array}$ & $\begin{array}{l}\text { Contributes to better operated } \\
\text { landfill reducing public health } \\
\text { and environmental effects of } \\
\text { waste dumps; contributes to } \\
\text { renewable energy supply }\end{array}$ & $\begin{array}{l}\text { ACM0001 and AMS- } \\
\text { III.G }\end{array}$ & $\mathrm{CH}_{4} / \mathrm{kg}$ (IPCC 2006) \\
\hline $\begin{array}{l}\text { Recycling and use of } \\
\text { more durable products }\end{array}$ & $\begin{array}{l}\text { Avoided waste disposal; } \\
\text { important source of incomes at } \\
\text { city level }\end{array}$ & - & $\mathrm{kWh} / \mathrm{kg}$ \\
\hline $\begin{array}{l}\text { Refuse derived fuel; } \\
\text { incineration }\end{array}$ & $\begin{array}{l}\text { Avoided waste disposal of } \\
\text { organic biomass that contributes } \\
\text { to better public health and } \\
\text { environmental effects of } \\
\text { disposal; contributes to } \\
\text { renewable energy supply }\end{array}$ & AMS-III.E & $\mathrm{CO}_{2} /$ tons of waste \\
\hline
\end{tabular}

For questions, inputs, suggestions contact: cbarreralaworldbank.org; cpetersonaworldbank.org

mechanism better implemented at a higher political jurisdiction than at the city level.

Another pricing mechanism that is better suited to urban areas is user charges tied to the quantity of waste disposed. Consumers who separate recyclables pay a lower fee for waste disposal. This pricing policy can work well in locations where waste collection is from individual households so that waste quantity for disposal can be readily monitored. In many areas in developing countries the use of communal collection points associated with multi-households such as apartments, the user charges are tied to quantity or volume and this approach may be impractical. 


\section{WATER AND WASTEWATER}

\section{Overview}

This section considers GHG emissions from water supply as well as wastewater treatment. GHG emissions in water supply primarily come from $\mathrm{CO}_{2}$ through the energy required for domestic water distribution. Cities such as Los Angeles, which need to transport their water over long distances, require considerable amounts of energy to provide water to their residents. Greenhouse gases from wastewater treatment are primarily methane and nitrous oxide, which have GWPs of 23 and 298,

FIGURE 11 Major sources of water supply for Los Angeles (recreated from CA Sustainability Alliance)

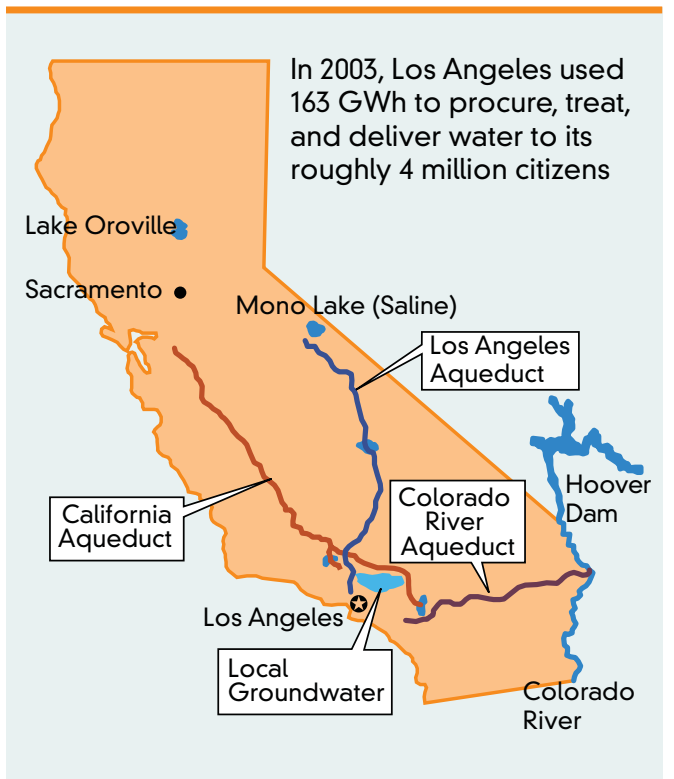

respectively. GHG emissions in this sector come from open sewers and wastewater collection The sludge resulting from wastewater treatment can also generate methane and nitrous oxide.

GHG emissions from wastewater and sludge are the result of microbial activity, generated at variable rates depending on parameters such as temperature, $\mathrm{pH}$, available substrates, microbial competition and many other factors (IPCC 2007d). Solid waste and wastewater treatment combined contribute to 3 percent of global GHG emissions (IPCC 2007a).

Most cities in developing countries currently lack proper infrastructure for water or wastewater services and the majority of their residents lack access to safe drinking water and basic sanitation. As the demand for these services continues to grow, the capital expenditure and resultant GHG emissions will correspondingly increase. The rapid pace of urbanization further affects cities as major efforts are required to maintain current coverage levels (WHO and UNICEF 2006).

Pollution of local water bodies is one of the primary problems created by the discharge of untreated wastewater and has long-term and large-scale negative impacts on public health and local ecosystems as well as on local and downstream water quality. Aquifers, rivers, lakes, and seas across the world are increasingly affected by water use and wastewater disposal practices in urban areas. Increased infrastructure coverage for wastewater services in developing countries can provide multiple 
preventive maintenance improved operational practices, e.g., which combination of pumps to operate, for how long, and at what time.

\section{Wastewater treatment}

Methane and nitrous oxide can potentially be generated during wastewater collection and treatment, depending on transport, treatment type, and operating conditions (IPCC 2007d). The treatment of wastewater is also associated with the production of sludge that can generate methane and nitrous oxide emissions.

A wide range of environmentally effective technologies are available to mitigate these emissions. The methane generated from anaerobic processes can be captured and flared or used to generated heat or electricity. The overview of measures to mitigate GHG wastewater emissions is presented in Table 5.

TABLE 5 Water and wastewater sector interventions, benefits, and quantification methods

\begin{tabular}{|c|c|c|c|}
\hline \multirow[b]{2}{*}{$\begin{array}{l}\text { Technology/ } \\
\text { Intervention }\end{array}$} & \multirow[b]{2}{*}{ Direct Local Benefits } & \multicolumn{2}{|c|}{ GHG Quantification Approach } \\
\hline & & $\begin{array}{l}\text { CDM } \\
\text { Methodology }\end{array}$ & $\begin{array}{l}\text { Indicator for } \\
\text { Estimation }\end{array}$ \\
\hline \multicolumn{4}{|l|}{ Water } \\
\hline $\begin{array}{l}\text { - Leak and water wastage } \\
\text { reduction } \\
\text { - Efficiency in water pumping } \\
\text { and improvement in } \\
\text { operation and maintenance } \\
\text { - Water-efficient household } \\
\text { appliances } \\
\text { - Low-flow toilets and } \\
\text { - showerheads } \\
\text { - Industrial water re-use }\end{array}$ & $\begin{array}{l}\text { Conservation of water resources } \\
\text { by reducing physical water leaks; } \\
\text { Cost saving from reduced energy } \\
\text { bills }\end{array}$ & $\begin{array}{l}\text { AM0020 } \\
\text { AMS IIC }\end{array}$ & $\mathrm{kWh} / \mathrm{m}^{3}$ \\
\hline \multicolumn{4}{|l|}{ Wastewater } \\
\hline $\begin{array}{l}\text { Wastewater treatment } \\
\text { optimization lanaerobic, } \\
\text { aerobic and sludge } \\
\text { treatment) }\end{array}$ & $\begin{array}{l}\text { Improved public health; Reduction } \\
\text { of odors; Better quality of effluent } \\
\text { discharged to surface water; } \\
\text { Advanced treated sludge can be } \\
\text { utilized as a land fertilizer }\end{array}$ & $\begin{array}{l}\text { AMS III.H } \\
\text { AMS III.I } \\
\text { ACM0014 } \\
\text { AM0080 }\end{array}$ & $\mathrm{CH}_{4} / \mathrm{kg}$ \\
\hline $\begin{array}{l}\text { - Leak and loss reductions } \\
\text { - Operations and } \\
\text { maintenance }\end{array}$ & $\begin{array}{l}\text { Improved public health; Reduction } \\
\text { of odors; Cost saving from avoided } \\
\text { purchase of grid electricity }\end{array}$ & AM0020 & $\mathrm{kWh} / \mathrm{m}^{3}$ \\
\hline $\begin{array}{l}\text { - Improved collection and } \\
\text { treatment }\end{array}$ & $\begin{array}{l}\text { Improved public health; Reduction } \\
\text { of odors; Better quality of effluent } \\
\text { discharged to surface water }\end{array}$ & - & $\mathrm{CH}_{4} / \mathrm{kg}$ \\
\hline
\end{tabular}

For questions, inputs, suggestions, contact: jgodinaworldbank.org 
Some approved CDM methodologies are applicable to greenfield activities, such as new wastewater treatment plants, which is important given that currently only 50 percent of the population in developing countries has access to improved sanitation (World Bank 2008) and this sector is likely to rapidly expand in the coming decades.

\section{URBAN FORESTRY}

\section{Overview}

Unlike the previous four sub-sections that describe sources of GHG emissions at the city level, this section discusses urban forestry, or green areas, which are sinks for greenhouse gases. Urban forestry in a city includes parks, gardens, avenue trees, and forested areas. These areas are considered GHG sinks because trees and plants absorb $\mathrm{CO}_{2}$ from the air, thus decreasing the amount of $\mathrm{CO}_{2}$ emitted into the atmosphere. Although urban forestry does not represent a major sink for global greenhouse gases, it can nevertheless offset a city's GHG emissions to a certain extent.

The process through which $\mathrm{CO}_{2}$ is removed from the atmosphere and stored in vegetation and soils is referred to as biological carbon sequestration. Reduction in greenhouse gases occurs through the ability of trees and plants to store carbon in trunks, branches, leaves, and roots, and recycle nutrients in the soil over the long-term.

\section{Local and GHG mitigation benefits of interventions}

Urban forestry is an important-but often ignored-element of urban land use planning. Integrating sustainable forestry into urban and peri-urban contexts offers opportunities for mitigation of $\mathrm{GHG}$ emissions and for promoting multiple environmental and social co-benefits, such as lower demand for heating and cooling, reduction in urban heat island effect, improvement in air quality, and reduced noise pollution.

Urban forests contribute to a reduction in heating and air conditioning requirements of the built environment by lowering air temperature in the summer and blocking cold winds in the winter. Simulated annual air conditioning savings (in $\mathrm{kWh}$ ) from tree plantings near insulated buildings are estimated to translate into $35-55$ percent of savings in energy when compared to uninsulated buildings (Simpson and McPherson 1996). Urban forests also contribute to a reduction in the urban heat island effect that manifests itself in the rise of surface and ambient air temperatures due to dense settlements, traffic movement, and concentrated economic activity in urban areas.

In addition to GHG mitigation benefits, urban forests contribute to environmental improvements in air and water quality, conservation of water resources, control of runoff, improvements in storm water drainage, and protection from the wind. Urban forests 


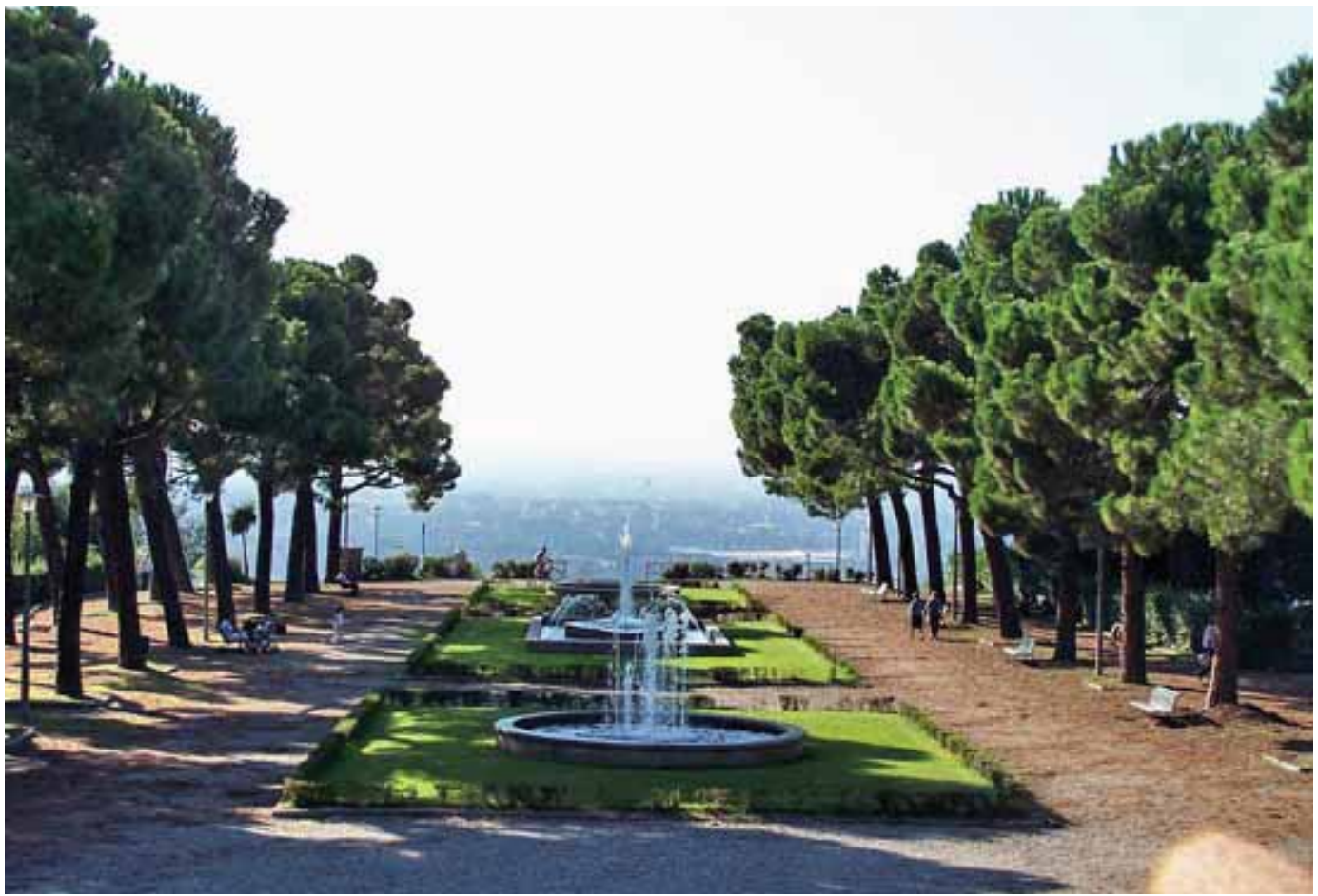

improve air quality by removing nitrogen dioxide, sulfur dioxide, carbon monoxide, ozone, and particulate matter as trees capture airborne particles on foliage, which is then washed off by rainwater, blown off by wind, or recycled into soil through leaf fall. Urban forests act as buffers to reduce noise pollution by up to 50 percent. Shading from avenue trees improves the longevity of paved roads and lowers GHG emissions associated with frequent road maintenance. Urban forests also support wildlife habitat by creating natural surroundings.

A healthy urban forest is a major municipal capital investment that increases the value of benefits between two and six times greater than the cost of tree planting and care (McPherson et al. 2005). Green areas yield large economic and social benefits in terms of improving air quality, increasing aesthetic values, enhancing property values, revitalizing communities, creating green jobs, and improving environmental awareness. Urban forests, parks, and mixed land use reduce vehicular traffic, encourage pedestrian traffic, and foster community cohesion.

City officials should take into account urban forest strategies that cover 20- to 40-year time horizons in their municipal environmental initiatives, city level climate actions, and 
sustainability plans. City governments could encourage or partner with local non-profit groups to supplement volunteer tree planting and maintenance initiatives. Collaboration with local educational institutions, electrical utilities, landscape architects, landscape maintenance firms, and public and private nurseries can facilitate cost effective implementation and monitoring of urban forestry programs.

Methodologies to quantify the GHG mitigation potential of specific land-use mitigation activities in urban contexts have been developed under both the mandatory and voluntary carbon markets. Current CDM methodologies cover interventions that result in GHG removal on land along transportation infrastructure (e.g., streets, waterways, power cables), near human settlements (e.g., athletic fields, lawns, golf courses), and forestation activities on degraded lands, croplands, and grasslands in urban and peri-urban areas. Table 6 provides a summary of the methodologies.

In addition to urban forestry, urban and periurban agriculture can play a major role in promoting soil carbon sequestration through sustainable agriculture and horticulture, recycling of organic wastes through composting, manure management, encouraging wastewater reuse, and improved tillage. This could also contribute to energy savings as locally grown food reduces the need for transport and refrigeration requirements significantly and

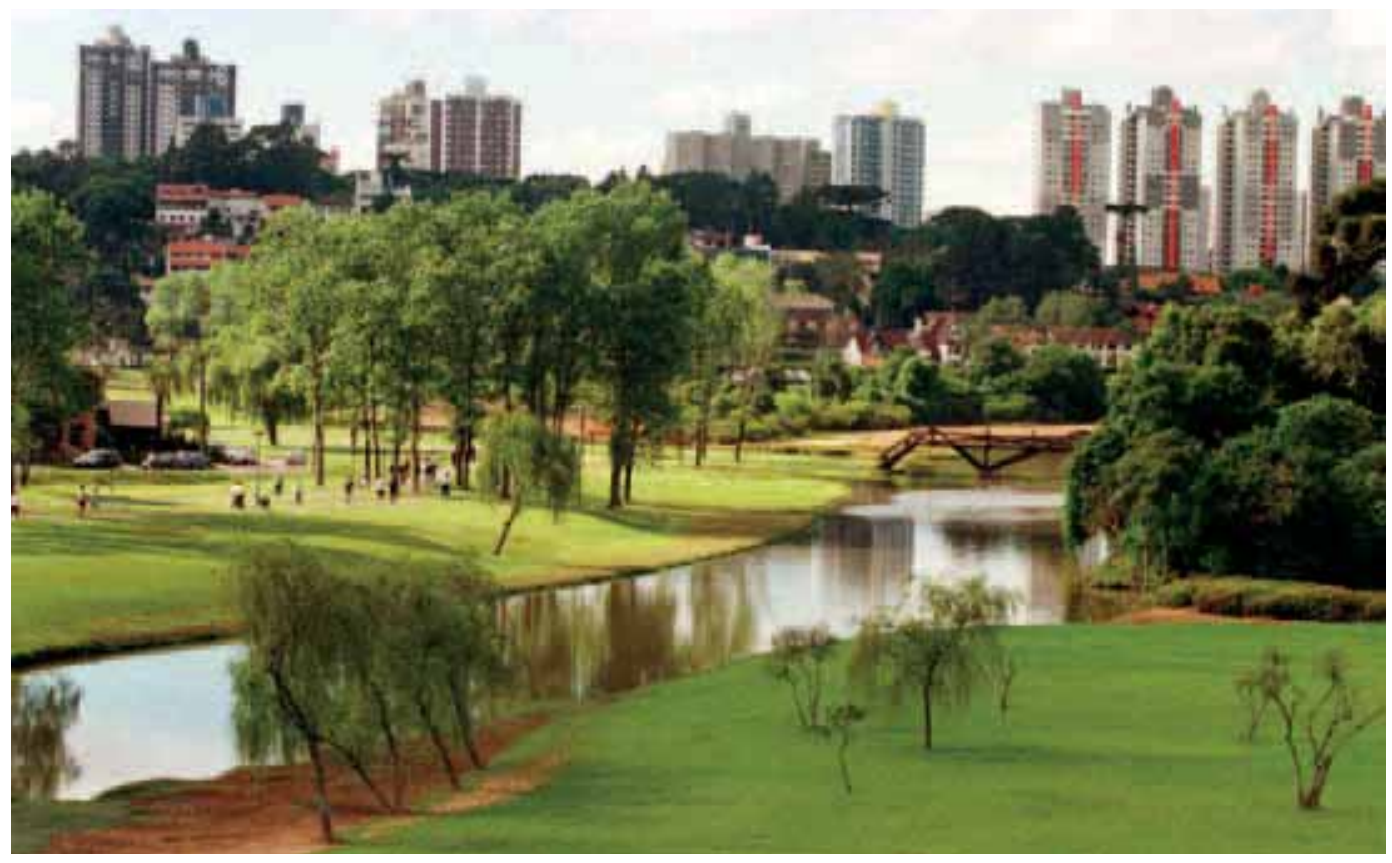


TABLE 6 Urban forestry sector interventions, benefits, and quantification methods

\begin{tabular}{|c|c|c|c|}
\hline \multirow[b]{2}{*}{$\begin{array}{l}\text { Technology/ } \\
\text { Intervention }\end{array}$} & \multirow[b]{2}{*}{ Direct Local Benefits } & \multicolumn{2}{|c|}{ GHG Quantification Approach } \\
\hline & & $\begin{array}{l}\text { CDM } \\
\text { Methodology }\end{array}$ & $\begin{array}{l}\text { Indicator for } \\
\text { Estimation }\end{array}$ \\
\hline $\begin{array}{l}\text { Tree vegetation in public and } \\
\text { residential areas (road-side, } \\
\text { greenways, etc) }\end{array}$ & \multirow{2}{*}{$\begin{array}{l}\text { Reduction of urban heat island; } \\
\text { Improvement in air quality; } \\
\text { Promotion of non-motorized } \\
\text { transport; Reduction in noise } \\
\text { pollution; Community cohesion; } \\
\text { Aesthetic value }\end{array}$} & AR-AMS0002 & \multirow[t]{2}{*}{$\begin{array}{l}\text { Carbon stock (tC/ } \\
\text { unit of land) }\end{array}$} \\
\hline $\begin{array}{l}\text { Afforestation; Reforestation; } \\
\text { Natural regeneration in peri- } \\
\text { urban areas }\end{array}$ & & $\begin{array}{l}\text { AR-ACM0001 } \\
\text { AR-AMS0001 }\end{array}$ & \\
\hline
\end{tabular}

For questions, inputs, comments, contact: rreddy1aworldbank.org

improves the shelf-life of perishable products. Social benefits of improved urban agricultural practices include better health and nutrition as well as increased livelihood opportunities for people living in and around cities.

Garden farms can implement productive landscaping; sustainable urban kitchen farms can adopt improved production methods and recycle organic wastes; green roofs and vertical farms can utilize space in densely populated urban areas not only to provide income and easy access to food but also to potentially decrease energy costs. Soil carbon sequestration is currently not eligible under the CDM but projects could estimate their impact using voluntary market rules and other estimation methods. 


\section{SECTION V}

\section{Qualifications}

The city-wide approach to carbon finance draws upon the programmatic approach under CDM and explores the opportunity to expand the scope of the CDM PoA by including multiple sectors and methodologies. This new approach is well suited for cities as they are geographically distinct and can establish coordination offices to implement programs across different sectors.

The approach as presented in this document is a simple aggregation of CDM methodologies and is limited by methodological requirements. Due to their primary focus on ensuring environmental integrity, CDM methodologies have very specific requirements for monitoring and verification. Furthermore, the currently available methodologies do not cover all possible technologies. While CDM PoA can support the implementation of a policy, quantification of ER benefits could use project-based methodologies.

As many of the 'measurement' approaches provided in the CDM methodologies are complex and impractical for projects with small volumes of emission reductions, this document proposes the use of simplified 'estimation' approaches. Cities can select the appropriate approach based on city-specific circumstances. The 'estimation' approach encompasses various tools and models used by sector experts. Both approaches can be expanded as more methodologies become available. Readers are encouraged to identify appropriate approaches and share them with the authors for inclusion in future editions of this document.

NOTE: This document details an innovative approach being developed by the Carbon Finance Unit and the Urban Developmentand Local Government Unit of the World Bank. The current rules and guidelines under the CDM are not directly applicable to this approach. This approach will be submitted to the CDM Executive Board for consideration and approval before CERs can be generated under the CDM. All information provided in this document should be used accordingly. For more information, contact mranade@worldbank.org; npinnoi@worldbank.org 


\section{Abbreviations and Acronyms}

\begin{tabular}{|c|c|}
\hline ACEEE & American Council for an Energy Efficient Economy \\
\hline BRT & Bus rapid transit \\
\hline $\mathrm{CCI}$ & Clinton Climate Initiative \\
\hline CDM & Clean Development Mechanism \\
\hline CDP & City Development Plan \\
\hline CER & Certified Emission Reduction \\
\hline CFCB & Carbon Finance Capacity Building \\
\hline $\mathrm{CH}_{4}$ & Methane \\
\hline $\mathrm{CH}_{4} / \mathrm{kg}$ & Methane per kilogram (of waste or other material) \\
\hline $\mathrm{CHP}$ & Combined heat and power \\
\hline $\mathrm{CNG}$ & Compressed natural gas \\
\hline $\mathrm{CO}_{2} \mathrm{e}$ & Carbon dioxide equivalent \\
\hline $\mathrm{CPF}$ & Carbon Partnership Facility \\
\hline $\mathrm{DH}$ & District heating \\
\hline DOE & Designated Operational Entity \\
\hline EECI & Energy Efficient Cities Initiative \\
\hline $\mathrm{ER}$ & Emission reductions \\
\hline ESMAP & Energy Sector Management Assistance Program \\
\hline ETS & European Trading Scheme \\
\hline GHG & Greenhouse gas(es) \\
\hline GWP & Global warming potential \\
\hline HEAT & Harmonized Emissions Analysis Tool \\
\hline HOT & High-occupancy toll \\
\hline $\mathrm{HOV}$ & High-occupancy vehicles \\
\hline IPCC & Intergovernmental Panel on Climate Change \\
\hline IEA & International Energy Agency \\
\hline JI & Joint Implementation \\
\hline JNNURM & Jawaharlal Nehru National Urban Renewal Mission \\
\hline $\mathrm{kg} / \mathrm{km}$ & Kilogram per kilometer (e.g., of fuel consumption by a vehicle) \\
\hline $\mathrm{kJ} / \mathrm{unit}$ & Kilojoules per unit (e.g., for gasoline, CNG, distance) \\
\hline $\mathrm{km}$ & kilometer \\
\hline $\mathrm{kWh}$ & Kilowatt hour \\
\hline $\mathrm{kWh} / \mathrm{km}$ & kilowatt hour per kilometer (e.g., of roads with streetlights) \\
\hline $\mathrm{kWh} / \mathrm{kg}$ & Kilowatt hour per kilogram (e.g., of coal in a power plant) \\
\hline $\mathrm{kWh} / \mathrm{m}^{2}$ & Kilowatt hour per square meter (e.g., heat supply in a building) \\
\hline
\end{tabular}




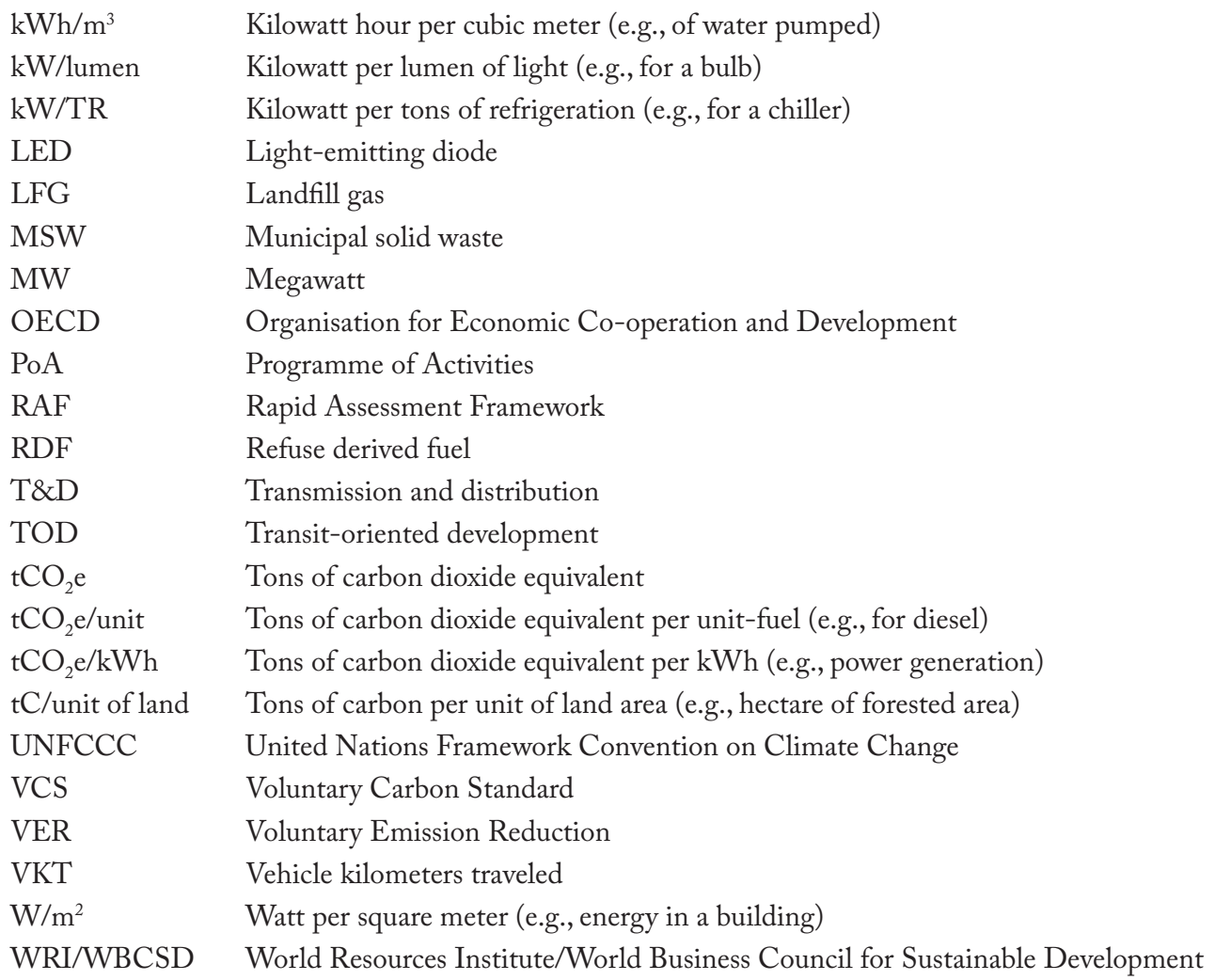


All definitions are from IPCC, UNFCCC and CDM documents

Additionality: Reduction in emissions by sources or enhancement of removals by sinks that is additional to any that would occur in the absence of a Joint Implementation (JI) or a Clean Development Mechanism (CDM) project activity as defined in the Kyoto Protocol Articles on JI and CDM. This definition may be further broadened to include financial, investment, technology, and environmental additionality. Under financial additionality, the project activity funding is additional to existing Global Environmental Facility, other financial commitments of parties included in Annex I, Official Development Assistance, and other systems of cooperation. Under investment additionality, the value of the Emission Reduction Unit/Certified Emission Reduction Unit shall significantly improve the financial or commercial viability of the project activity. Under technology additionality, the technology used for the project activity shall be the best available for the circumstances of the host party. Environmental additionality refers to the environmental integrity of the claimed amount by which greenhouse gas emissions are reduced due to a project relative to its baseline. A project activity is further additional, if the incentive from the sale of emission allowances helps to overcome barriers to its implementation.

Baseline scenario or business-as-usual: The baseline for a CDM project activity is the scenario that reasonably represents the anthropogenic emissions by sources of greenhouse gases (GHG) that would occur in the absence of the proposed project activity. A baseline shall cover emissions from all gases, sectors, and source categories within the project boundary. Different scenarios may be elaborated as potential evolutions of the situation existing before the proposed project activity. The continuation of a current activity could be one of them; implementing the proposed project activity may be another; and many others could be envisaged.

Boundary: The project boundary shall encompass all anthropogenic emissions by sources of greenhouse gases (GHG) under the control of the project participants that are significant and reasonably attributable to the $\mathrm{CDM}$ project activity.

Carbon dioxide $\left(\mathrm{CO}_{2}\right): \mathrm{CO}_{2}$ is a naturally occurring gas and a by-product of burning fossil fuels or biomass, of land-use changes and of industrial processes. It is the principal anthropogenic greenhouse gas that affects Earth's radiative balance. It is the reference gas against which other greenhouse gases are measured and therefore it has a Global Warming Potential of 1.

CDM (Clean Development Mechanism): Defined in Article 12 of the Kyoto Protocol, the CDM is intended to meet two objectives: (i) to assist parties not included in Annex I in achieving sustainable development and in contributing to the ultimate objective of the convention; and (ii) to assist parties included in Annex I in achieving compliance with their quantified emission limitation and reduction 
commitments. Certified Emission Reduction Units from CDM projects undertaken in Non-Annex I countries that limit or reduce GHG emissions, when certified by operational entities designated by Conference of the Parties/Meeting of the Parties, can be accrued to the investor (government or industry) from parties in Annex B. A share of the proceeds from certified project activities is used to cover administrative expenses as well as to assist developing country parties that are particularly vulnerable to the adverse effects of climate change to meet the costs of adaptation.

\section{Certified Emission Reduction Unit (CER):}

Equal to one metric tonne of $\mathrm{CO}_{2}$-equivalent emissions reduced or sequestered through a Clean Development Mechanism project, calculated using Global Warming Potentials. In order to reflect potential non-permanence of afforestation and reforestation project activities, the use of temporary certificates for Net Anthropogenic Greenhouse Gas Removal was decided by COP 9 .

$\mathrm{CO}_{2} \mathrm{e}$ (Carbon dioxide equivalent): The amount of $\mathrm{CO}_{2}$ emission that would cause the same radiative forcing as an emitted amount of a well mixed greenhouse gas, or a mixture of well mixed greenhouse gases, all multiplied with their respective Global Warming Potentials to take into account the differing times they remain in the atmosphere.

Emission factor: An emission factor is the rate of emission per unit of activity, output or input. E.g. a particular fossil fuel power plant could have a emission factor of $0.765 \mathrm{kgCO}_{2} \mathrm{e} / \mathrm{kWh}$ generated.

Emission reduction: Equal to one metric tonne of $\mathrm{CO}_{2}$-equivalent emissions reduced or sequestered arising from a Joint Implementation (defined in Article 6 of the Kyoto Protocol) project.
Global Warming Potential: An index, based upon radiative properties of well-mixed greenhouse gases, measuring the radiative forcing of a unit mass of a given well-mixed greenhouse gas in the present-day atmosphere integrated over a chosen time horizon, relative to that of $\mathrm{CO}_{2}$. The GWP represents the combined effect of the differing times these gases remain in the atmosphere and their relative effectiveness in absorbing outgoing thermal infrared radiation. The Kyoto Protocol is based on GWPs from pulse emissions over a 100-year time frame.

Greenhouse gases: Greenhouse gases are those gaseous constituents of the atmosphere, both natural and anthropogenic, that absorb and emit radiation at specific wavelengths within the spectrum of infrared radiation emitted by the Earth's surface, the atmosphere, and clouds. This property causes the greenhouse effect. Water vapor $\left(\mathrm{H}_{2} \mathrm{O}\right)$, carbon dioxide $\left(\mathrm{CO}_{2}\right)$, nitrous oxide $\left(\mathrm{N}_{2} \mathrm{O}\right)$, methane $\left(\mathrm{CH}_{4}\right)$, and ozone $\left(\mathrm{O}_{3}\right)$ are the primary greenhouse gases in the Earth's atmosphere. Apart from $\mathrm{CO}_{2}$, $\mathrm{N}_{2} \mathrm{O}$, and $\mathrm{CH}_{4}$, the Kyoto Protocol deals with the greenhouse gases sulphur hexafluoride $\left(\mathrm{SF}_{6}\right)$, hydrofluorocarbons (HFCs), and perfluorocarbons (PFCs).

Hydrofluorocarbons (HFCs): One of the six gases or groups of gases to be curbed under the Kyoto Protocol. They are produced commercially as a substitute for chlorofluorocarbons or as a by-product in chemical production. HFCs are largely used in refrigeration and semiconductor manufacturing. Their Global Warming Potentials range from 1,300 to 11,700 .

IPCC: The Intergovernmental Panel on Climate Change (IPCC) is an intergovernmental, scientific body for the assessment of climate change, established by the United Nations Environment 
Programme (UNEP) and the World Meteorological Organization (WMO) to provide the world with a clear scientific view on the current state of climate change and its potential environmental and socioeconomic consequences. IPCC reviews and assesses the most recent scientific, technical, and socioeconomic information produced worldwide relevant to the understanding of climate change.

Leakage: Leakage is defined as the net change of anthropogenic emissions by GHG sources which occurs outside the project boundary, and which is measurable and attributable to the CDM project activity.

Methane $\left(\mathrm{CH}_{4}\right)$ : Methane is one of the six greenhouse gases to be mitigated under the Kyoto Protocol. It is the major component of natural gas and associated with all hydrocarbon fuels, animal husbandry, and agriculture.

Monitoring: Monitoring refers to the collection and archiving of all relevant data necessary for determining the baseline, measuring anthropogenic emissions by sources of greenhouse gases (GHG) within the project boundary of a CDM project activity and leakage, as applicable.

Nitrous oxide $\left(\mathrm{N}_{2} \mathrm{O}\right)$ : One of the six types of greenhouse gases to be curbed under the Kyoto Protocol.

Perfluorocarbons (PFCs): Among the six greenhouse gases to be abated under the Kyoto Protocol. These are by-products of aluminum smelting and uranium enrichment. They also replace chlorofluorocarbons in manufacturing semiconductors. The Global Warming Potential of PFCs is 6500-9200.

Sulphur hexafluoride $\left(\mathrm{SF}_{6}\right)$ : One of the six greenhouse gases to be curbed under the Kyoto Protocol. It is largely used in heavy industry to insulate high-voltage equipment and to assist in the manufacturing of cable-cooling systems and semiconductors. Its Global Warming Potential is 23,900. 


\section{References}

\section{Introduction}

IEA. 2008. World Energy Outlook 2008. Paris: International Energy Agency.

\section{Section I: Cities and Climate Change}

Angel, S., S. Sheppard, and D. Civco. 2005.

The Dynamics of Global Urban Expansion.

Washington, DC: The World Bank.

IEA (International Energy Agency). 2008. World

Energy Outlook 2008. Paris: International

Energy Agency.

IPCC. 2007a. Summary for Policymakers. In:

Climate Change 2007: The Physical Science Basis.

Contribution of Working Group I to the Fourth

Assessment Report of the Intergovernmental Panel on Climate Change [Solomon, S., D. Qin, M.

Manning, Z. Chen, M. Marquis, K.B. Averyt,

M.Tignor and H.L. Miller (eds.)]. Cambridge,

UK and New York, NY: Cambridge University Press.

Kennedy, C.A., A. Ramaswami, S. Carney, S.

Dhakal. 2009. Greenhouse Gas Emission Baselines

for Global Cities and Metropolitan Regions.

Commissioned research paper presented at the 5th Urban Research Symposium, June 28-30, 2009, Marseilles, France. Washington, DC: The World Bank.

Rogner, H.-H., D. Zhou, R. Bradley. P. Crabbé, O.

Edenhofer, B.Hare (Australia), L. Kuijpers, and M. Yamaguchi. 2007. Introduction. In Climate Change 2007: Mitigation. Contribution of Working Group III to the Fourth Assessment Report of the Intergovernmental Panel on Climate Change [B. Metz, O.R. Davidson, P.R. Bosch, R. Dave, L.A. Meyer (eds.)]. Cambridge
University Press, Cambridge, UK and New York, NY: Cambridge University Press.

United Nations. 2007. World Urbanization Prospects:

The 2007 Revision Population Database. New

York: United Nations.

World Bank. 2010. World Development Report:

Development and Climate Change.

Washington, DC: The World Bank.

\section{Section II: Accessing Carbon Finance}

$C D M$ website (methodologies, glossary of terms, PoA

procedures): cdm.unfccc.int

State ES Trends of the Carbon Markets, 2009: www. carbonfinance.org

$\mathrm{C}_{4} \mathrm{O}$ Cities Climate Leadership Group: www.c40cities. org.

Eco ${ }^{2}$ Cities: Ecological Cities as Economic Cities: www. worldbank.org/eco2.

Mexico City Climate Action Program 2008-2012 Summary. 2008. [Martínez, O. V., B. Cárdenas, S. Alvarez (eds.)]. Secretaría del Medio Ambiente Gobierno del Distrito Federal. Johnson, T., C. Alatorre, Z. Romo, F. Liu. 2009. Low-Carbon Development for Mexico. Washington, DC: The World Bank. Ward, M, J. Garibaldi, K. Hampton, N. Hohne, M. Jung, A. Bakir, and S. Gray. 2008. Policy instruments and approaches for scaling up investment in climate change mitigation activities. Washington, DC: The World Bank.

\section{Section III: Creating a City-wide} Approach to Reduce GHG Emissions A Primer on CDM Programme of Activities: www. cd4cdm.org/guidebooks 
PoA Blueprint Book: www.kfw-foerderbank.de/EN_ Home/KfW_Carbon_Fund/index.jsp

Carbon Finance Capacity Building: www. lowcarboncities.info.

Energy Efficient Cities Initiative: www.esmap.org. Greenhouse Gas Index for Cities: www.worldbank. org/urban.

India City Development Plans under the Jawaharlal Nehru National Urban Renewal Mission (JNNURM): http://jnnurm.nic.in/ nurmudweb/brochure.aspx

Project $2^{\circ}$ : www.project2degrees.org.

Suzuki, H., A. Dastur, S. Moffat, N. Yabuki. 2009. $\mathrm{Eco}^{2}$ Cities: Ecological Cities as Economic Cities. Washington, DC: The World Bank.

\section{Section IV: Sectors and Interventions} Energy

Efficiency 2.0, Behavior as a Resource: http:// efficiency20.com/market_info/behavior_as_ resource.html.

IEA (International Energy Agency). 2008. World Energy Outlook 2008. Paris: International Energy Agency.

IPCC. 2007b. Climate Change 2007: Synthesis Report. Contribution of Working Groups I, II and III to the Fourth Assessment Report of the Intergovernmental Panel on Climate Change [Core Writing Team, Pachauri, R.K and A. Reisinger (eds.)]. Geneva: IPCC.

IPCC. 2007c. Climate Change 2007: The Physical Science Basis. Contribtuion of Working Group I to the Fourth Assessment Report of the Intergovernmental Panel on Climate Change. Cambridge, UK: Cambridge University Press.

\section{Transport}

IPCC. 2007a. Summary for Policymakers. In: Climate Change 2007: The Physical Science Basis. Contribution of Working Group I to the Fourth
Assessment Report of the Intergovernmental Panel on Climate Change [Solomon, S., D. Qin, M. Manning, Z. Chen, M. Marquis, K.B. Averyt, M.Tignor and H.L. Miller (eds.)]. Cambridge, UK and New York, NY: Cambridge University Press.

\section{Solid Waste}

Hiramatsu A., Y. Hara, M. Sekiyama, R. Honda, and C. Chiemchaisri. 2009. Municipal solid waste flow and waste generation characteristics in an urban-rural fringe area in Thailand. Waste Management E Research 27(10):951-960.

Hoornweg, D., P. Lam, and M. Chaudhry. 2005. Waste management in China: Issues and Recommendations. Urban Development Working Papers, Working Paper No. 9. Washington, DC: The World Bank.

IPCC. 2007a. Summary for Policymakers. In: Climate Change 2007: The Physical Science Basis. Contribution of Working Group I to the Fourth Assessment Report of the Intergovernmental Panel on Climate Change [Solomon, S., D. Qin, M. Manning, Z. Chen, M. Marquis, K.B. Averyt, M.Tignor and H.L. Miller (eds.)]. Cambridge, UK and New York, NY: Cambridge University Press.

IPCC. 2007d. Bogner, J., M. Abdelrafie Ahmed, C. Diaz, A. Faaij, Q. Gao, S. Hashimoto, K. Mareckova, R. Pipatti, T. Zhang. Waste Management. In Climate Change 2007: Mitigation. Contribution of Working Group III to the Fourth Assessment Report of the Intergovernmental Panel on Climate Change [B. Metz, O.R. Davidson, P.R. Bosch, R. Dave, L.A. Meyer (eds)]. Cambridge, UK and New York, NY: Cambridge University Press. ISWA. 2009. Waste and Climate Change. ISWA White Paper. Vienna: International Solid Waste Association. 


\section{Specific Opportunities and Case Studies in the Transport Sector}

Anas and G. R. Timilsina. 2009. Impacts of Policy instruments to Reduce Congestion and Emissions from Urban Transportation: The Case of Sao Paulo, Brazil. World Bank Policy Research Working Paper 5099. Washington, DC: The World Bank.

Cambridge Systematics. 2009. Moving Cooler: An Analysis of Transportation Strategies for Reducing Greenhouse Gas Emissions. Prepared for the Moving Cooler Steering Committee. Washington, DC: Urban Land Institute.

GTZ. 2004. Air Quality Management - Sustainable Transport: A Sourcebook for Policy-Makers in Developing Cities, Module 5a.

GTZ. 2006. Cleaner Fuels and Vehicle Technologies - Sustainable Transport: A Sourcebook for Policy-Makers in Developing Cities, Module 4a.

McKinsey and Company. 2009. Pathways to a Low-Carbon Economy. Version 2 of the Global Greenhouse Gas Abatement Cost Curve.

Reddy, R. and S. Guttikunda 9(eds). 2006. Promoting Global Environmental Priorities in the Urban Transport Sector: Experience from World Bank Group - Global Environmental Facility Projects. Washington, DC: The World Bank.

Shipper, L., C. Marie-Lillie, and R. Gorham. 2000. Flexing the Link between Transport and Greenhouse Gas. Paris: International Energy Agency.

Vegara, W., and S. Haeussling. 2007. Transport and Climate: Lessons from the Partnership between Mexico City and the World Bank. Latin America and the Caribbean Region Sustainable Development Working Paper \#29. Washington, DC: The World Bank.

\section{Models for Estimating GHG Emissions from the Transport Sector}

Argonne National Laboratory. The Greenhouse Gases, Regulated Emissions, and Energy use in

Transportation (GREET) Model.

European Environment Agency. COPERT-4.

GHG Protocol. Cross Sector Calculation Tool: GHG Emissions from Transport for Mobile Sources.

National Academy of Sciences Transportation Research Board. Assessment of Greenhouse Gas Analysis

Techniques for Transportation Project. National Cooperative Highway Research Program. Project 25-25; Task 17.

Transport Canada. User Guide for Urban Transportation Emissions Calculator (UTEC).

United States Environmental Protection Agency. Motor Vebicle Emissions Simulator.

Peterson, C. 1979. Excise Tax on New Tires Proposed: Scrap Tires Arise As Special Disposal Problem. Waste Age.

Peterson, C. 2009. Cities and Solid Waste. Sector Note 4. Field Reference Guide. Eco² Cities:
Ecological Cities as Economic Cities.

Washington, DC: The World Bank.

Water and Wastewater

CA Sustainability Alliance. Water Agency Profile:

City of Los Angeles. 
IPCC. 2007a. Summary for Policymakers. In: Climate Change 2007: The Physical Science Basis. Contribution of Working Group I to the Fourth Assessment Report of the Intergovernmental Panel on Climate Change [Solomon, S., D. Qin, M. Manning, Z. Chen, M. Marquis, K.B. Averyt, M.Tignor and H.L. Miller (eds.)]. Cambridge, UK and New York, NY: Cambridge University Press.

IPCC. 2007d. Bogner, J., M. Abdelrafie Ahmed, C. Diaz, A. Faaij, Q. Gao, S. Hashimoto, K. Mareckova, R. Pipatti, T. Zhang. Waste Management. In Climate Change 2007: Mitigation. Contribution of Working Group III to the Fourth Assessment Report of the Intergovernmental Panel on Climate Change [B. Metz, O.R. Davidson, P.R. Bosch, R. Dave, L.A. Meyer (eds)]. Cambridge, UK and New York, NY: Cambridge University Press.

Kingdom, B., R. Liemberger, P. Marin P. 2006. The Challenge of Reducing Non-Revenue Water (NRW) in Developing Countries. Water Supply and Sanitation Sector Board Discussion Paper No.8. Washington, DC: The World Bank.
World Bank. 2008. The Millennium Development Goals. Environmental Indicators for 2008, Improved sanitation facilities (\% of population with access). Development Data Group. Washington, D.C.

World Health Organization (WHO) and United Nations Children's Fund (UNICEF) 2006. Meeting the MDG drinking water and sanitation target: The urban and rural challenge of the decade.

\section{Urban Forestry}

Simpson, J. and G. McPherson. 1996. Estimating Urban Forest Impacts on Climate-Mediated Residential Energy Use. $12^{\text {th }}$ Conference on Meteorology and Aerobiology. January 28 February 2, 1996. Atlanta, GA, USA.

McPherson, E.G., J.R. Simpson, P.J. Peper, S.E. Maco, S.L. Gardner, S.K. Cozad, and Q.Xiao. 2005. Midwest community tree guide: benefits, costs and strategic planting. Davis, CA: Center for Urban Forest Research, Pacific Southwest Research Station, USDA Forest Service. 


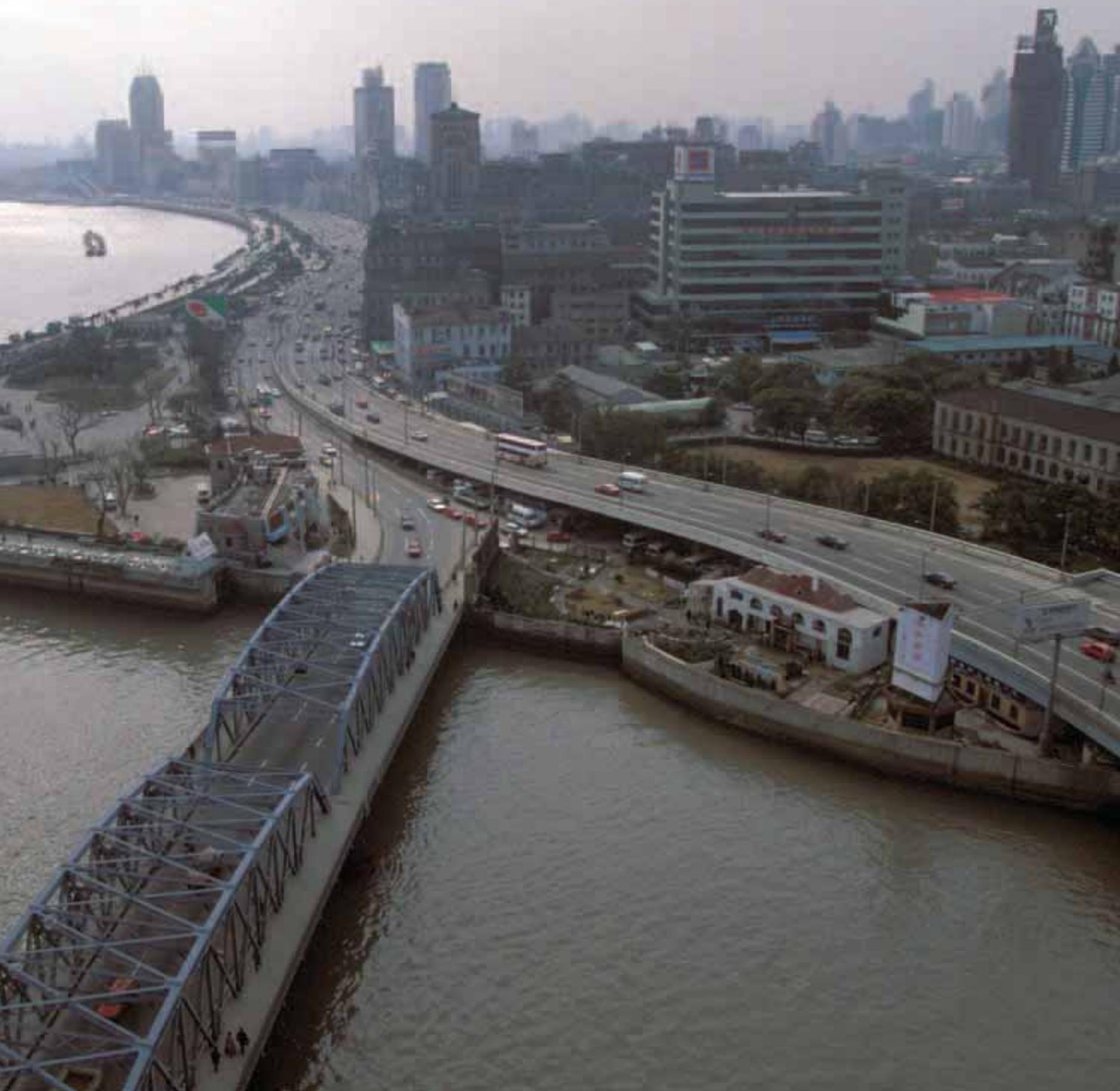




\section{CDM Approved Methodologies}

Available at http://cdm.unfccc.int/methodologies/index.html

CDM Methodology Number Title

\begin{tabular}{|c|c|}
\hline AR-AM002 & Restoration of degraded lands through afforestation/reforestation \\
\hline AR-ACM0001 & Afforestation and reforestation of degraded land \\
\hline AM0020 & Water pumping efficiency improvement \\
\hline AM0060 & Power saving through replacement by efficient chillers \\
\hline AM0080 & $\begin{array}{l}\text { Mitigation of greenhouse gases emissions with treatment of wastewater } \\
\text { in aerobic wastewater treatment plants }\end{array}$ \\
\hline ACM0014 & $\begin{array}{l}\text { Mitigation of greenhouse gas emissions from treatment of industrial } \\
\text { wastewater }\end{array}$ \\
\hline AMS II.C & Demand-side energy efficiency programmes for specific technologies \\
\hline AMS III.H & Methane recovery in wastewater treatment \\
\hline AMS III.I & $\begin{array}{l}\text { Avoidance of methane production in wastewater treatment through } \\
\text { replacement of anaerobic lagoons by aerobic systems }\end{array}$ \\
\hline AMS III.AE & $\begin{array}{l}\text { Energy efficiency and renewable energy measures in new residential } \\
\text { buildings }\end{array}$ \\
\hline AMS II.J & Demand-side activities for efficient lighting technologies (deemed savings) \\
\hline AMS II.A & $\begin{array}{l}\text { Supply side energy efficiency improvements - transmission and } \\
\text { distribution }\end{array}$ \\
\hline AM0067 & Installation of energy efficient transformers in a power distribution grid \\
\hline AMS II.B & Supply side energy efficiency improvements - generation \\
\hline AM0044 & $\begin{array}{l}\text { Energy efficiency improvement projects: boiler rehabilitation or } \\
\text { replacement in industrial and district heating sectors }\end{array}$ \\
\hline AM0058 & Introduction of a new primary district heating system \\
\hline AM0061 & $\begin{array}{l}\text { Rehabilitation and/or energy efficiency improvement in existing power } \\
\text { plants }\end{array}$ \\
\hline AM0062 & $\begin{array}{l}\text { Energy efficiency improvement of a power plant through retrofitting } \\
\text { turbines }\end{array}$ \\
\hline ACM0002 & Grid-connected electricity generation from renewable sources (no biomass) \\
\hline
\end{tabular}




\section{CDM Methodology Number Title}

\begin{tabular}{|c|c|}
\hline AMS I.D & Renewable electricity generation for a grid \\
\hline AMS I.C & Thermal energy production with or without electricity \\
\hline AMS I.A & Electricity generation by the user \\
\hline AM0072 & Fossil fuel displacement by geothermal resources for space heating \\
\hline ACM0016 & Mass Rapid Transit Projects \\
\hline AM0031 & Baseline methodology for Bus Rapid Transit Project \\
\hline AMS III.U & Cable Cars for Mass Rapid Transit System (MRTS) \\
\hline ACM0017 & Production of biodiesel for use as fuel \\
\hline AMS III.T & Plant oil production and use for transport applications \\
\hline AM0019 & $\begin{array}{l}\text { Renewable energy project replacing the electricity of one single fossil } \\
\text { plant (excluding biomass) }\end{array}$ \\
\hline AMS III.AA & Transportation energy efficiency activities using retrofit technologies \\
\hline AMS III.C & Emission reductions by low-greenhouse emission vehicles \\
\hline AMS III.S & Introduction of low-emission vehicles to commercial vehicle fleets \\
\hline AM0025 & $\begin{array}{l}\text { Avoided emissions from organic waste through alternative waste } \\
\text { treatment processes }\end{array}$ \\
\hline AMS III.E & $\begin{array}{l}\text { Avoidance of methane production from biomass decay through controlled } \\
\text { combustion }\end{array}$ \\
\hline AMS III.F & Avoidance of methane production from biomass decay through composting \\
\hline AM0083 & Avoidance of landfill gas emissions by in-situ aeration of landfills \\
\hline AMS III.A.F & $\begin{array}{l}\text { Avoidance of methane emissions through excavating and composting of } \\
\text { partially decayed municipal solid waste (MSW) }\end{array}$ \\
\hline ACM0001 & Landfill gas project activities \\
\hline AMS III.G & Landfill methane recovery \\
\hline
\end{tabular}




\section{Carbon Partnership Facility (CPF)}

The World Bank has been a pioneer, catalyst and facilitator helping to shape the global carbon market for 10 years. It has contributed to developing what was initially a risky untested market into a now vibrant market. With the Carbon Partnership Facility (CPF), the World Bank is now pioneering the next generation of carbon finance for the post-2012 world. The World Bank's knowledge, experience, global network, credibility with the private sector and special relationship with developing countries make it particularly well-positioned for the task.

The CPF intends to develop programmatic and sector-based approaches in developing countries to reduce greenhouse gas emissions. It will be used in areas such as the power sector, energy efficiency, gas flaring, transport, waste management systems and urban development. The flexible structure of the $\mathrm{CPF}$ also enables it to explore the use of carbon finance to promote the introduction of cuttingedge technologies and solutions, such as carbon capture and storage.

The new approach of the CPF can help catalyze change in developing countries and nations with economies in transition towards lower carbon development paths and help modernize their infrastructure. The CPF is intended to demonstrate how scaling up investment in clean technologies and modern infrastructure solutions can work, using carbon finance to help transform sectors and deliver social and economic co-benefits in the developing world.

The CPF provides a platform for partnership between buyers and sellers, and developed and developing countries, to integrate carbon finance into sustainable economic development and policy. Ultimately, the $\mathrm{CPF}$ aims to make a significant contribution to the use of carbon finance in mitigation of global climate change.

\section{Urban development}

Cities are the fastest growing source of greenhouse gas emissions. While urban areas provide better quality of life to their burgeoning population through services such as water supply, waste management, mass transport, and other public utilities, these services are also the source of major emissions. Most cities are straddled with financial burdens due to the fast pace of growth and competing socioeconomic demands and are unable to assess or mitigate their emissions. The CPF intends to work with cities and municipalities to create umbrella emission reduction programs that support mitigation activities across sectors. These programs aim to allow the inclusion of all small and large sources of greenhouse gas emissions and move the cities towards a low carbon growth path. 

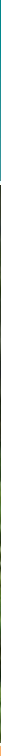